\title{
Synchronized Polarization Induced Electrospray: Comprehensively Profiling Biomolecules in Single Cells by Combining both Positive-ion and Negative-ion Mass Spectra
}

Jun Hu, Xiao-Xiao Jiang, Jiang Wang, Qi-Yuan Guan, Pan-Ke Zhang, Jing-Juan Xu*, Hong-Yuan Chen

State Key Laboratory of Analytical Chemistry for Life Science and Collaborative Innovation Center of Chemistry for Life Sciences, School of Chemistry and Chemical Engineering, Nanjing University, Nanjing 210023, China

*Corresponding author. Tel/Fax: +86-25-89687294; E-mail address: xujj@nju.edu.cn 


\section{Contents}

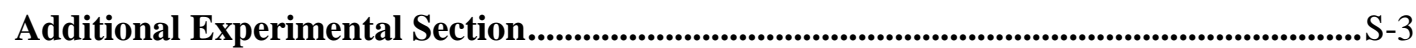

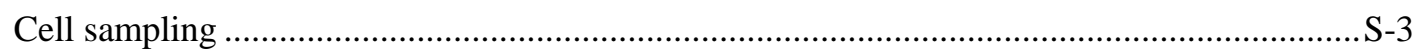

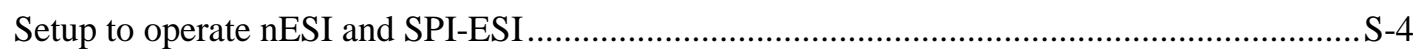

Figures and Tables ............................................................................................................................................ S-5

Figure S1. Characterization of the emitters and Single-cell sampling ..................................... S-5

Figure S2. Comparison of the robustness of the glass tip in nESI and SPI-ESI ....................... S-6

Figure S3. Comparison of MS signal stability using DC polarization and AC-SWV polarization

Figure S4. Mass spectra of Met-Enkephalin analyzed by SPI-ESI .......................................... S-8

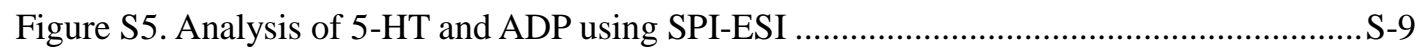

Figure S6. Dark-field images of SPI-ESI and nESI …………………................................. S-10

Figure S7. Comparison of spray flow rate achieved by SPI-ESI and nESI ...............................

Figure S8. The selection of solvents for the analysis of single PC-12 cells............................. S-12

Figure S9. The mass spectra of different samples analyzed by nESI and SPI-ESI ....................S-13

Figure S10. Determination of the volume of single PC-12 cells and the volume of sampled cell content.

Figure S11. Typical tandem mass spectra obtained from single Allium cepa cell samples.......S-15

Figure S12. Typical tandem mass spectra obtained from single PC-12 cell samples................. S-16

Table S1. Negative ion assignments from single Allium cepa cell samples based on accurate mass measurements. S-17

Table S2. Positive ion assignments from single Allium cepa cell samples based on accurate mass measurements S-18

Table S3. Negative ion assignments from single PC-12 cell samples based on accurate mass measurements S-22

Table S4. Positive ion assignments from single PC-12 cell samples based on accurate mass measurements 


\section{Additional Experimental Section}

\section{Cell Sampling}

Plant cells and mammalian cells have different cytoarchitecture and volume. Therefore, different sampling procedures were used. Allium cepa epidermal cells are relatively large (up to $500 \mu \mathrm{m}$, Figure $\mathrm{S} 1(\mathrm{f}))$, the emitter tip $(\sim 1.2 \mu \mathrm{m}$, Figure $\mathrm{S} 1(\mathrm{~b}))$ could be directly inserted into the cells. The liquid cell content of a single Allium cepa epidermal cell could be sucked into the tip of the emitter by the capillary force, and a syringe was also used in this case to provide negative pressure for sucking the cell content. The sampled liquid cell content of a single Allium cepa epidermal cell was about $300 \mathrm{pL}$ (Figure S8(b)) and could be directly analyzed without further treatments such as dilution. PC-12 cells are relatively small and cultured in physiological environment. Therefore, a smaller tip $(0.6 \mu \mathrm{m}$, Figure $\mathrm{S} 8(\mathrm{~d}))$ was used for the biopsy sampling. $1 \mu \mathrm{L}$ solvent was loaded into the capillary before the biopsy sampling for several purposes: 1) minimizing the entered solution when the emitter was immersed into PBS (the PC-12 cells were cultured in PBS during the biopsy sampling). PBS could not only produce interfering background peaks during MS analysis, but also cause clogging of the capillary by crystallization before or during mass spectrometric analysis if no solvent was loaded in advance. 2) diluting the cell content of single PC-12 cells. The PC-12 cells have very viscous cytoplasm and the sampled volume of the cell content was relatively small (about $0.2 \mathrm{pL}$, Figure S10). Therefore, the dilution was necessary, even ultralow spray flow rate was achieved in our case. And it should be noted that the sampled cell content was diluted only in the tip region of the capillary $(\sim 30 \mathrm{pL})$ with a dilution ratio of analyte:solvent $=1: 150$, not in the whole solvent of $1 \mu \mathrm{L}$, which could be indicated by the MS signal duration (see Figure 3) and the flow rate (see Figure S6). The solvent was retained in the tip region and acted as the assistant solvent in the mass spectrometric analysis. 


\section{Setup to Operate nESI and SPI-ESI}

nESI was operated in a wire-in-capillary mode: a grounded copper wire $(\sim 50 \mu \mathrm{m})$ was inserted into the emitter from its end part and contacted with the solution, see Figure S6. The emitter was placed in front of the Vcap (MS inlet) with a distance of 5 mm. In our case, a high voltage of $2.5 \mathrm{kV}$ was applied to the Vcap. The applied voltage should be in coordination with the distance between the emitter and Vcap, the opening of the emitters, etc. A distance of $5 \mathrm{~mm}$ was optimized for efficient transmission of the electrospray generated charged droplets/ions and to avoid rapid evaporation of the small volume liquid sample by the heated drying gas $($ Temp $=$ $300{ }^{\circ} \mathrm{C}$, Flow rate $=2 \mathrm{~L} / \mathrm{min}$ ). The corona discharge (see Figure S2(c)), especially in negative-ion mode, could lead structural damage of the emitters when the voltage was abnormal high $(>3.0 \mathrm{kV})$. In this case, a high voltage of $2.5 \mathrm{kV}$ was optimized for the consideration of the robustness of the emitters and ionization efficiency (see Figure S2). To make an efficient solution-electrode contact, $1 \mu \mathrm{L}$ methanol water (50:50) was loaded into the emitters after the sampling of single Allium cepa cells to perform nESI. Judging from the MS signal duration (see Figure 3) and the flow rate (see Figure S6), the dilution ratio of analyte/solvent was about 1:30.

As was shown in Figure S6, SPI-ESI was operated using a noncontact one-electrode protocol: any physical contact between the electrode and the solution was avoided. Parameters such as the applied potential on the Vcap were identical with those in nESI. Cyanoacrylate glue (Deli) could also be used to seal emitter openings when needed. In SPI-ESI, a mode switching frequency of $0.5 \mathrm{~Hz}$ (cycle time $=2 \mathrm{~s}$ ) was chosen for the consideration of MS signal intensity. In our mass spectrometer (Q-ToF 6530b, Agilent Technologies Inc.), the MS signal intensity is directly proportional to the number of transients/spectrum. Typically, the number of transients per spectrum is about 10000 at $0.5 \mathrm{~Hz}$ and is about 5000 at $1 \mathrm{~Hz}$. It means that the MS signal intensity at $1 \mathrm{~Hz}$ was only half of that at $0.5 \mathrm{~Hz}$. For this reason, $0.5 \mathrm{~Hz}$ was chosen for all the experiments. 


\section{Figures and Tables}

\section{Characterization of the emitters and Single-cell sampling}
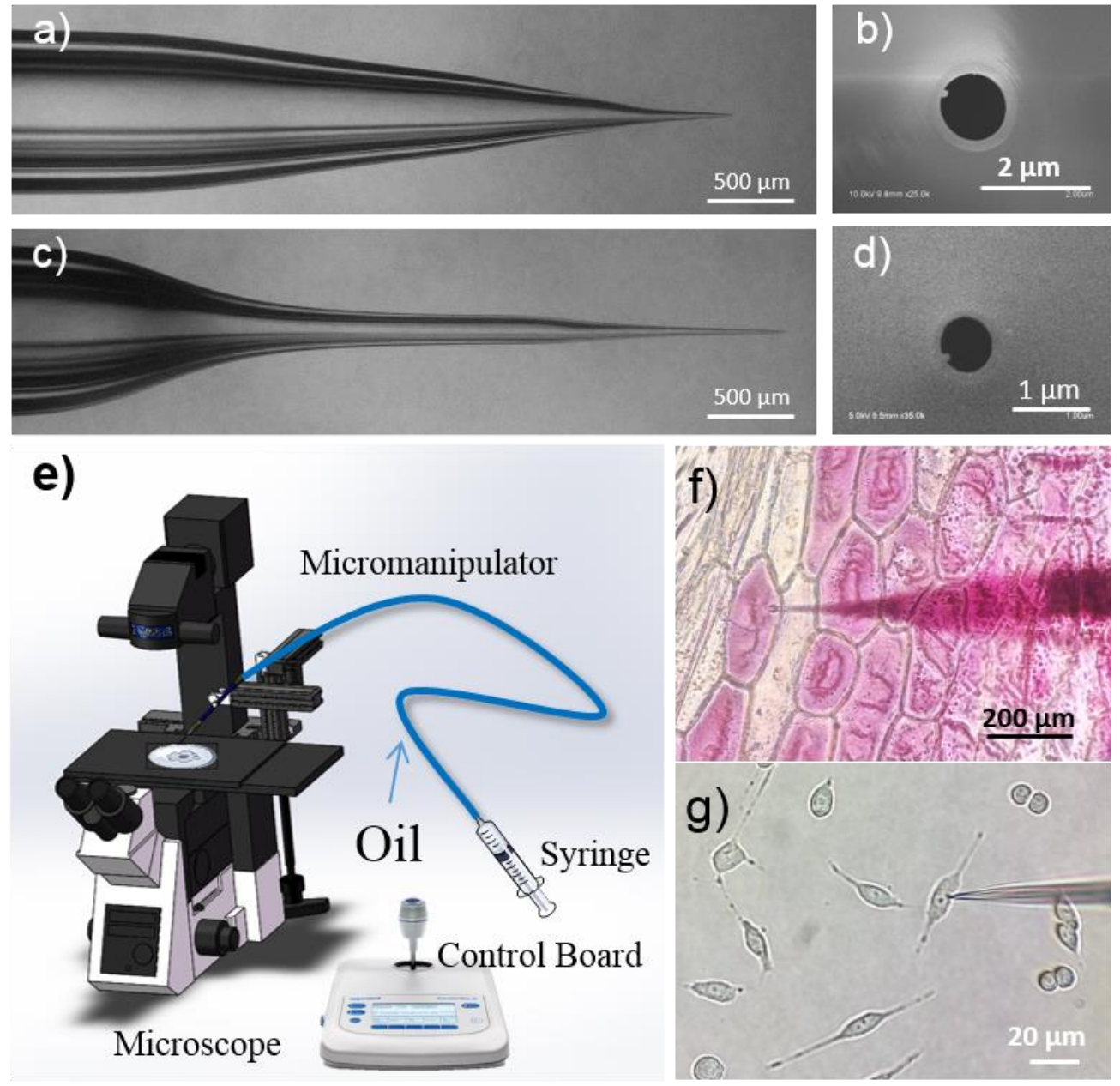

Figure S1. Characterization of the emitters and Single-cell sampling: a, b, f) an emitter with short tapering and an $\sim 1.2 \mu \mathrm{m}$ opening for single Allium cepa cell sampling; c, d, g) an emitter with long tapering and an $\sim 0.6 \mu \mathrm{m}$ opening for single PC-12 cell sampling. Optical images (a, c, f, g) were carried out on an inverted microscope (IX71, Olympus) equipped with a 4x objective and a true-color digital camera (DP73, Olympus). SEM images (b, d) were carried out on field emission scanning electron microscopy (S-4800, Hitachi). e) The setup to sample single cells with a pulled emitter held by a micromanipulator which was mounted on an inverted microscope, a syringe connected into the tip of the emitter for extracting cell content. 


\section{Comparison of the robustness of the glass tip in nESI and SPI-ESI.}

The images were carried out on an inverted microscope (IX71, Olympus) equipped with a dark-field condenser $(0.8<\mathrm{NA}<0.92)$, 10x objective (NA 0.7), a $100 \mathrm{~W}$ halogen lamp and a true-color digital camera (DP80, Olympus). The power of the halogen lamp was turned down to about 5\% to demonstrate the corona discharge clearly. That was the reason why the tip in Figure S2 $(a, c)$ looked dim and pale yellow. The corona discharge, which could lead structural damage of the tip, was not observed in SPI-ESI, even when a relatively high potential (up to $6 \mathrm{kV}$ ) was applied to the Vcap. In comparison with that in SPI-ESI, nESI was susceptible to the high voltage, the structure of the tip was destroyed after 10 minutes spray at $3.5 \mathrm{kV}$. In this manuscript, a relatively lower voltage $(2.5 \mathrm{kV})$ was used to avoid corona discharge in nESI.

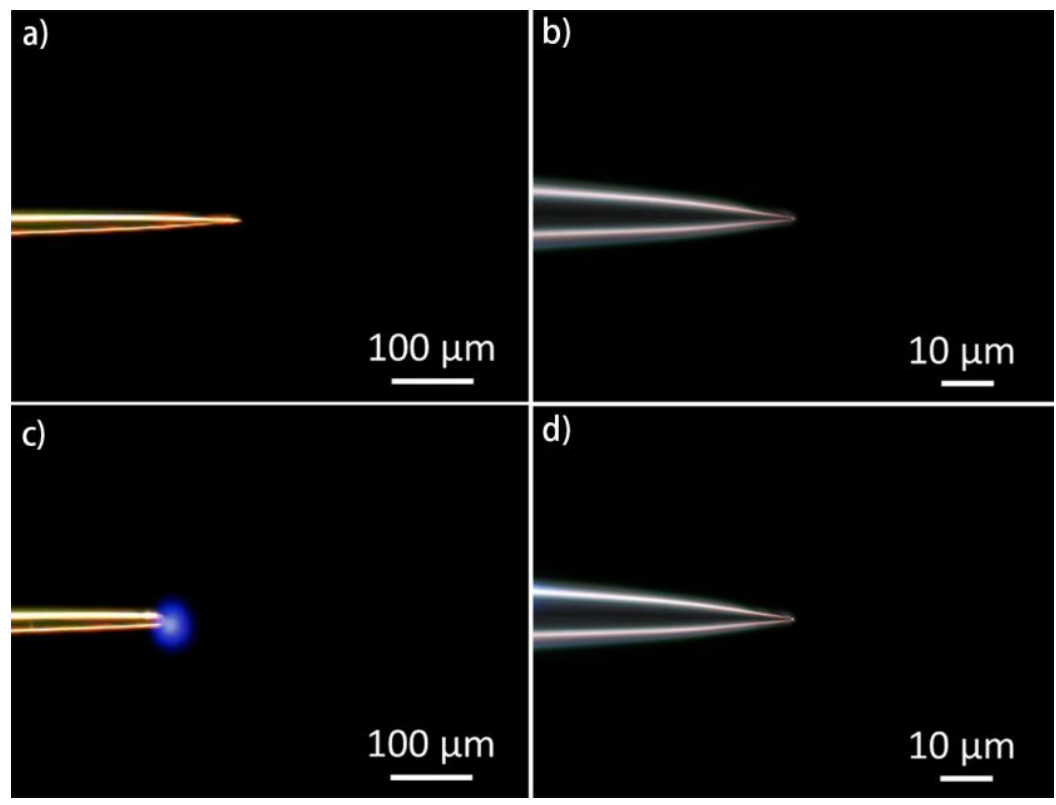

Figure S2. Dark-field images of nESI in negative-ion mode: a) before electrospray; c) after ten-minute electrospray. Dark-field images of SPI-ESI: b) before electrospray; d) after ten-minute electrospray. The opening of the emitters was $\sim 1.2 \mu \mathrm{m}$. The voltage was $3.5 \mathrm{kV}$. 


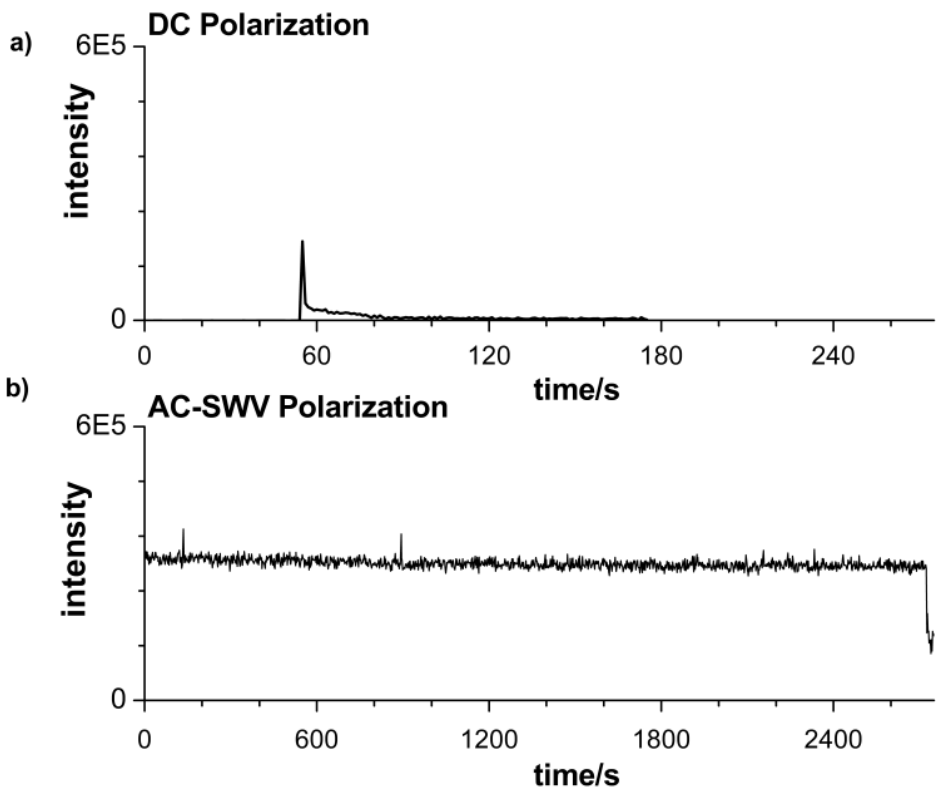

Figure S3. Comparison of MS signal stability using: a) DC polarization and b) AC-SWV polarization (Angiotensin II, $1 \mu \mathrm{M}, 1 \mu \mathrm{L}$ ). It should be mentioned that the MS signal termination in AC-SWV polarization experiment was not a result of exhaustion of solution, it was stopped manually after 45 minutes. 
a)

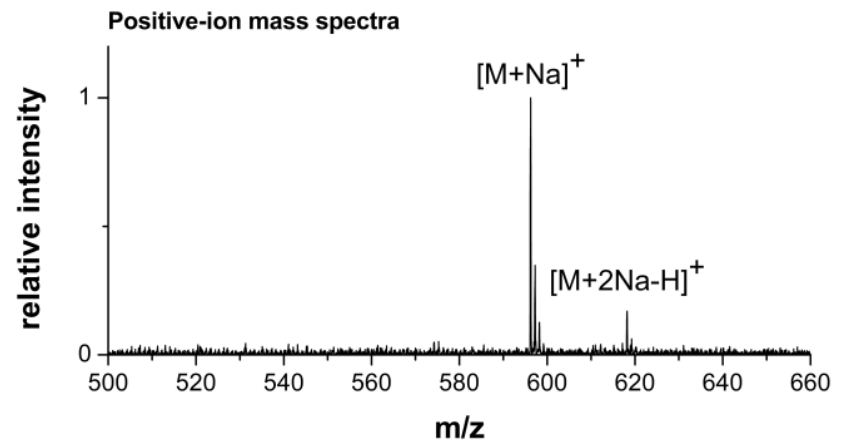

b)

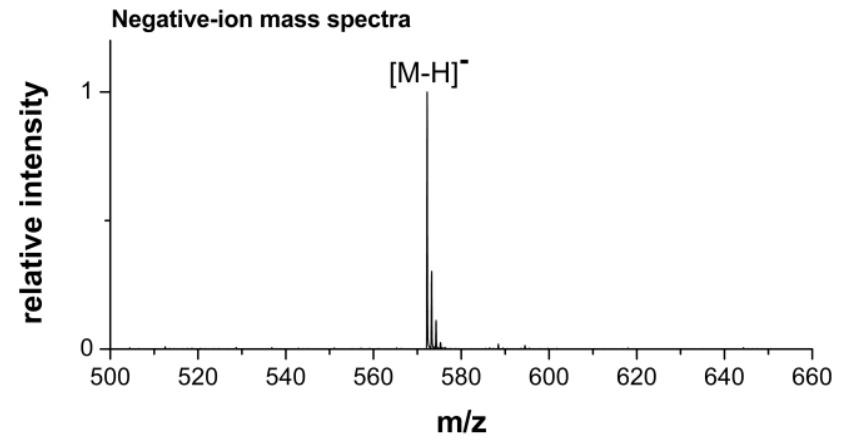

Figure S4. Mass spectra of Met-Enkephalin ( $0.2 \mathrm{ppm}, \mathbf{1} \boldsymbol{\mu L})$ analyzed by SPI-ESI: a) Extracted positive-ion mass spectrum; b) Extracted negative-ion mass spectrum. 


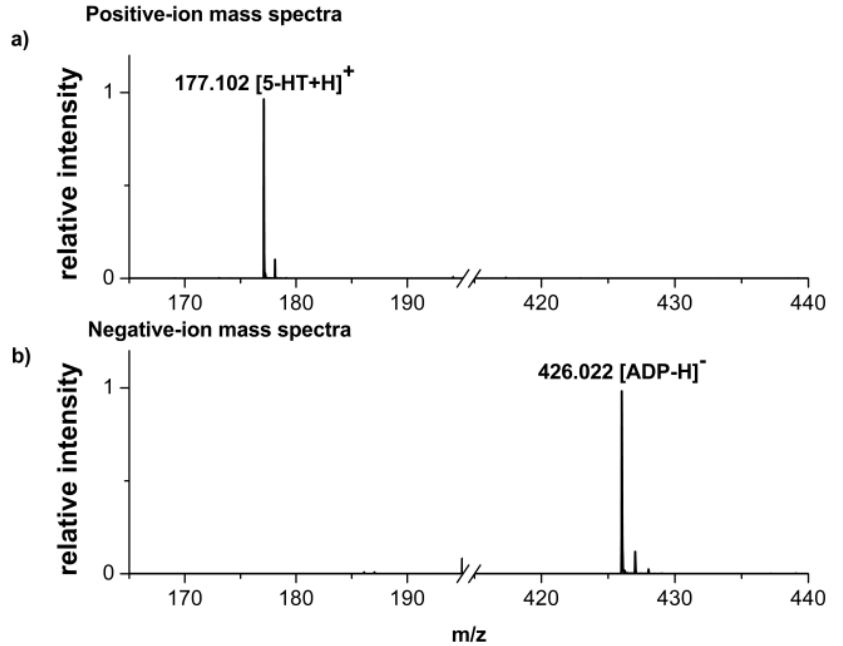

Figure S5. Analysis of 5-HT and ADP using SPI-ESI: a) extracted positive-ion mass spectrum; b) extracted negative-ion mass spectrum. The concentration was $100 \mathrm{ppb}$ for 5-HT and ADP. The volume was $1 \mu \mathrm{L}$. Methanol water (75:25) was used in SPI-ESI. 


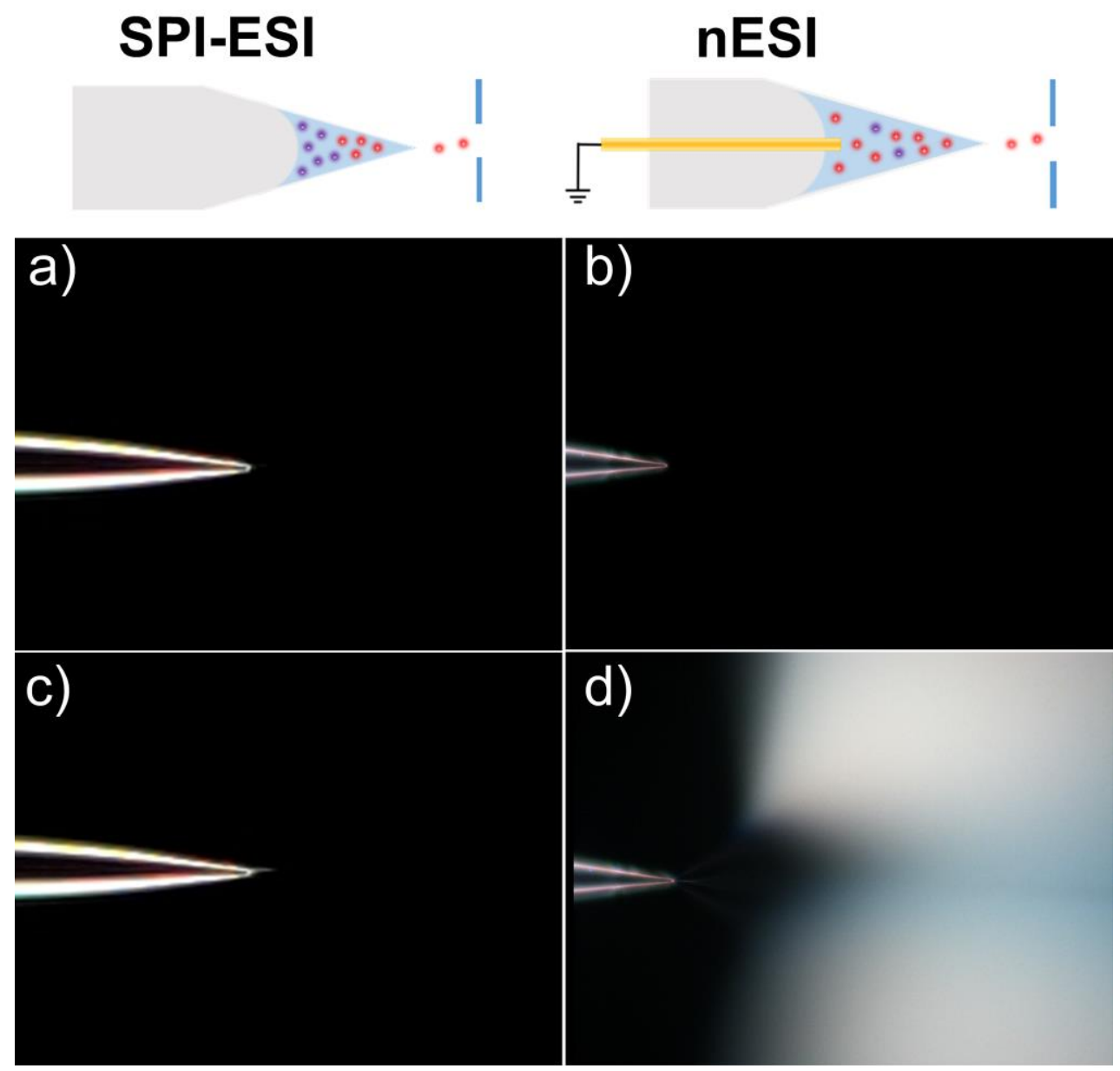

Figure S6. Dark-field images of SPI-ESI and nESI. a) SPI-ESI with AC-SWV off; b) nESI with AC-SWV off; c) SPI-ESI with AC-SWV on; d) nESI with AC-SWV on. SPI-ESI and nESI were performed using the same emitter with an $\sim 1.2 \mu \mathrm{m}$ opening. The emitters were pointed towards the traction electrode ( $\sim 5 \mathrm{~mm}$ away). The voltage on the Vcap was $2.5 \mathrm{kV}$. The images were carried out on an inverted microscope (IX71, Olympus) equipped with a dark-field condenser $(0.8<\mathrm{NA}<0.92), 10 \mathrm{x}$ objective (NA 0.7), a $100 \mathrm{~W}$ halogen lamp and a true-color digital camera (DP80, Olympus). 


\section{Comparison of spray flow rate achieved by SPI-ESI and nESI.}

On average, the flow rate was $\sim 26 \mathrm{pL} / \mathrm{min}$ in SPI-ESI and $\sim 30 \mathrm{~nL} / \mathrm{min}$ in $\mathrm{nESI}$. For determination of the flow rate of SPI-ESI, picoliter sample solution was sucked into the tip of the emitters by capillary force and the help of the syringe. The opening in Figure S7(c) was $\sim 0.6 \mu \mathrm{m}$. The volume of sample solution was calculated through conic bulk formula: $v=\frac{1}{12} \pi d^{2} h$, Figure S7(c). While for nESI, a relative larger bulk of sample solution (typically $10 \mu \mathrm{L}$, to make an efficient solution-electrode contact) was loaded into the emitters from the rear part. The spray was stopped manually when $4 \mathrm{~mm}$ of the fluid column was consumed. The estimated volume was $\sim 1$ $\mu \mathrm{L}$ (calculated by cylinder volume formula: $v=\frac{1}{4} \pi d^{2} h$. The internal diameter of the emitters (far away from the tip region) was $0.58 \mathrm{~mm}$, thus $\sim 1 \mu \mathrm{L}$ sample solution was consumed). 36.2, 33.6, 34.3 minutes were used in three individual tests, thus the average flow rate was $\sim 30 \mathrm{~nL} / \mathrm{min}$ in nESI. Similarly, the average flow rate in SPI-ESI was evaluated by three individual tests. 70, 315,429 seconds were used to consume the 50.6, 105.4, $104.2 \mathrm{pL}$ sample solutions, the corresponding flow rate was 43.1, 20.1, $14.5 \mathrm{pL} / \mathrm{min}$, respectively. Thus, the average flow was $\sim 26 \mathrm{pL} / \mathrm{min}$. It was obvious that SPI-ESI could achieve about three orders of magnitude sample economy compared with that of nESI.

a)

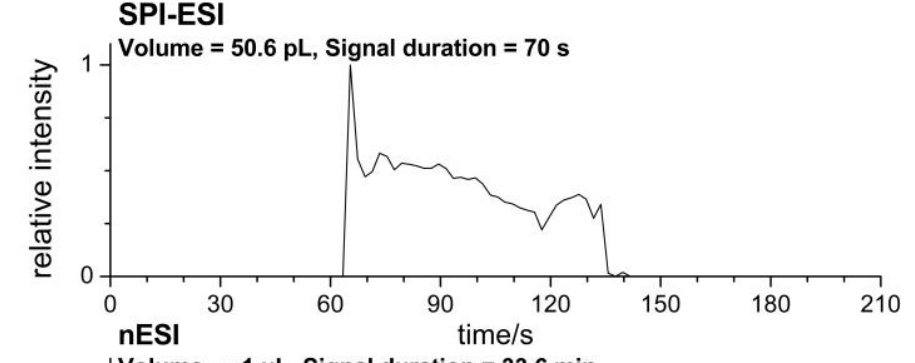

b)
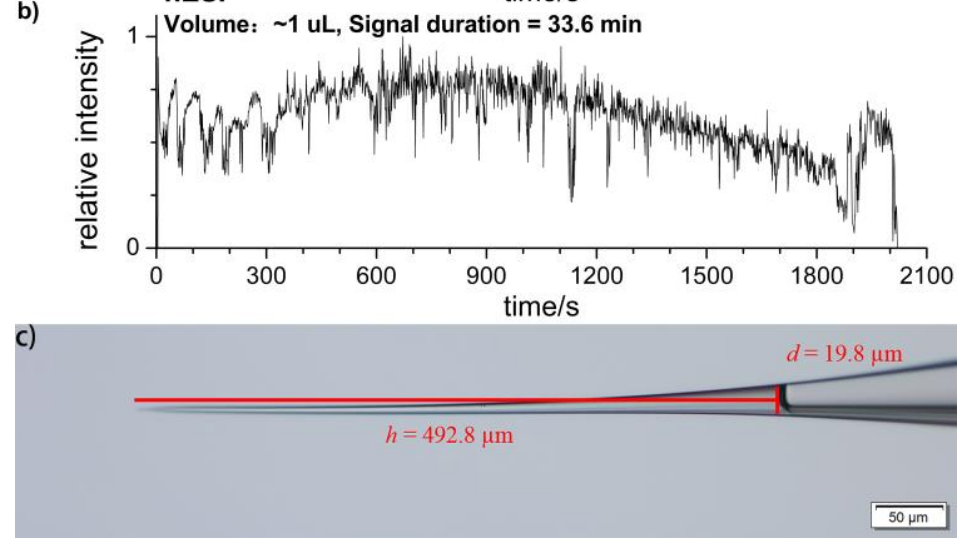

Figure S7. Typical signal duration achieved by: a) SPI-ESI; b) nESI. c) determination the volume of sample solution for SPI-ESI analysis. 
SPI-ESI

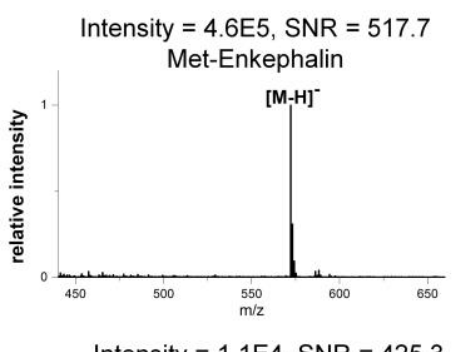

Fluorescein

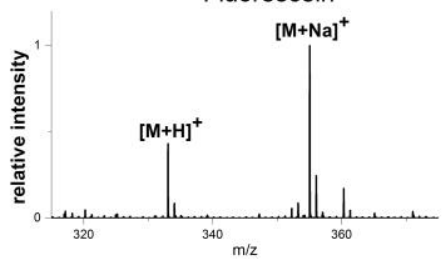

Intensity $=4.2 \mathrm{E} 4, \mathrm{SNR}=251.7$ ADP

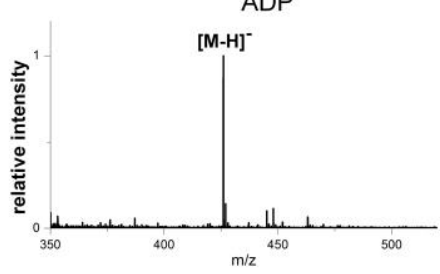

Intensity $=2.5 \mathrm{E} 5, \mathrm{SNR}=2745.5$

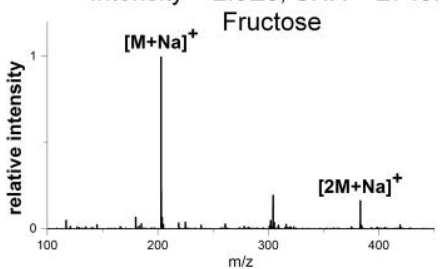

Intensity $=6.8 \mathrm{E} 3, \mathrm{SNR}=51.8$

Erythrosine

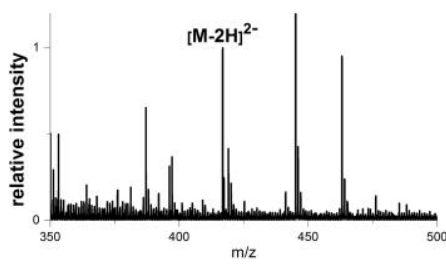

Intensity $=1.0 \mathrm{E} 4, \mathrm{SNR}=436.3$ 5-Hydroxytryptamine

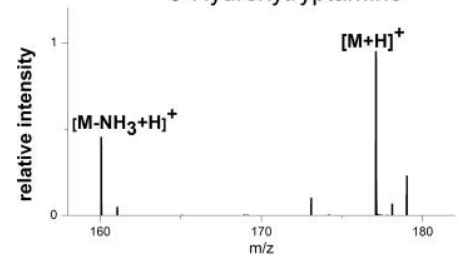

nESI

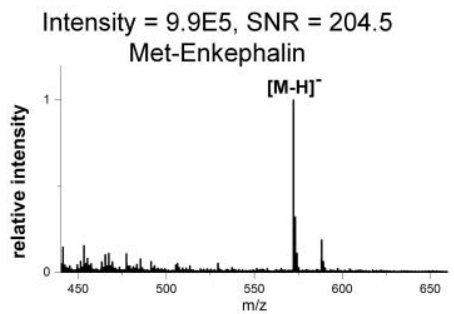

Intensity $=6.6 \mathrm{E} 4, \mathrm{SNR}=219.0$

Fluorescein

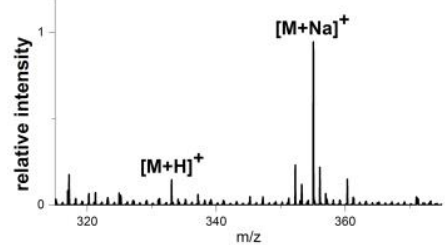

Intensity $=1.1 \mathrm{E} 5 \mathrm{SNR}=225.8$

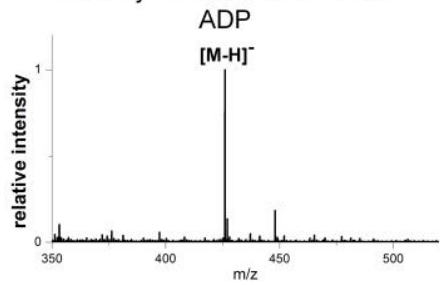

Intensity $=1.7 \mathrm{E} 6 \mathrm{SNR}=2380.1$

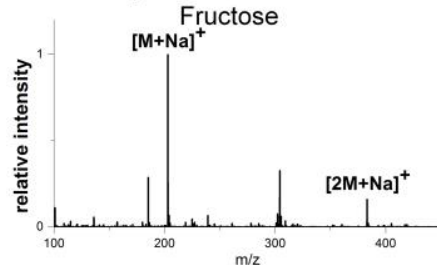

Intensity $=1.4 \mathrm{E} 4 \mathrm{SNR}=68.0$ Erythrosine

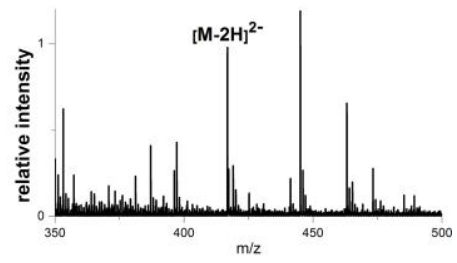

Intensity $=5.7 \mathrm{E} 4$ SNR $=350.3$ 5-Hydroxytryptamine

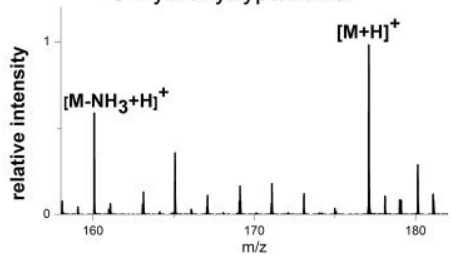

Figure S8. The mass spectra of different samples analyzed by nESI and SPI-ESI. The concentration was $1 \mathrm{ppm}$ for met-enkephalin, fluorescein, ADP, fructose, erythrosine, 5-HT, but 10 ppm for fructose. The volume of the sample solution was $1 \mu \mathrm{L}$. 


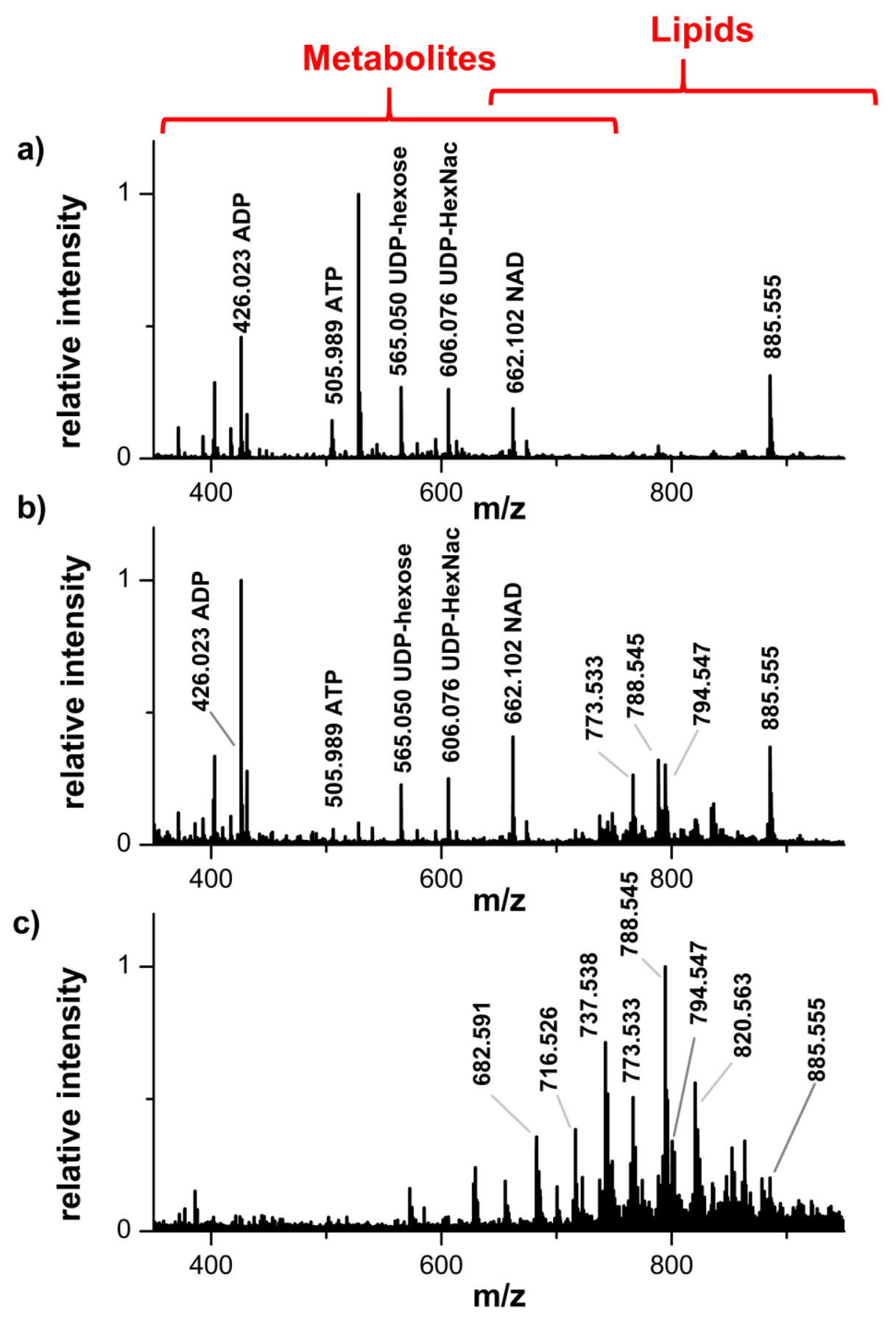

Figure S9. The selection of solvents for the analysis of single PC-12 cells. Analysis of single PC12 cells with different ionization solvents in SPI-ESI: a) pure water; b) methanol water (75:25); c) methanol chloroform (50:50). 


\section{Determination of the volume of single PC-12 cells and the volume of sampled cell content}

The volume of single PC-12 cells was measured using scanning ion conductance microscopy (SICM, ICnano2000, Ionscope Ltd.). The volume of single PC-12 cells ranges from 1.9 to $2.4 \mathrm{pL}$, and the average volume was $\sim 2.1 \mathrm{pL}$ (evaluated using six cells, their volumes were 1.91, 2.12, $2.15,2.21,2.26,2.43$, respectively). The volume was evaluated using SPIP software packages (version 6.6.0). Typically, the volume of sampled liquid content from single Allium cepa cells was about $300 \mathrm{pL}$. The volume of sampled liquid content from PC-12 was estimate to be $\sim 0.2 \mathrm{pL}$. Oil (Sigma, M8410) was loaded into the capillary prior to the sampling process and a clear interface could form between cell content and oil, see Figure S10(c).

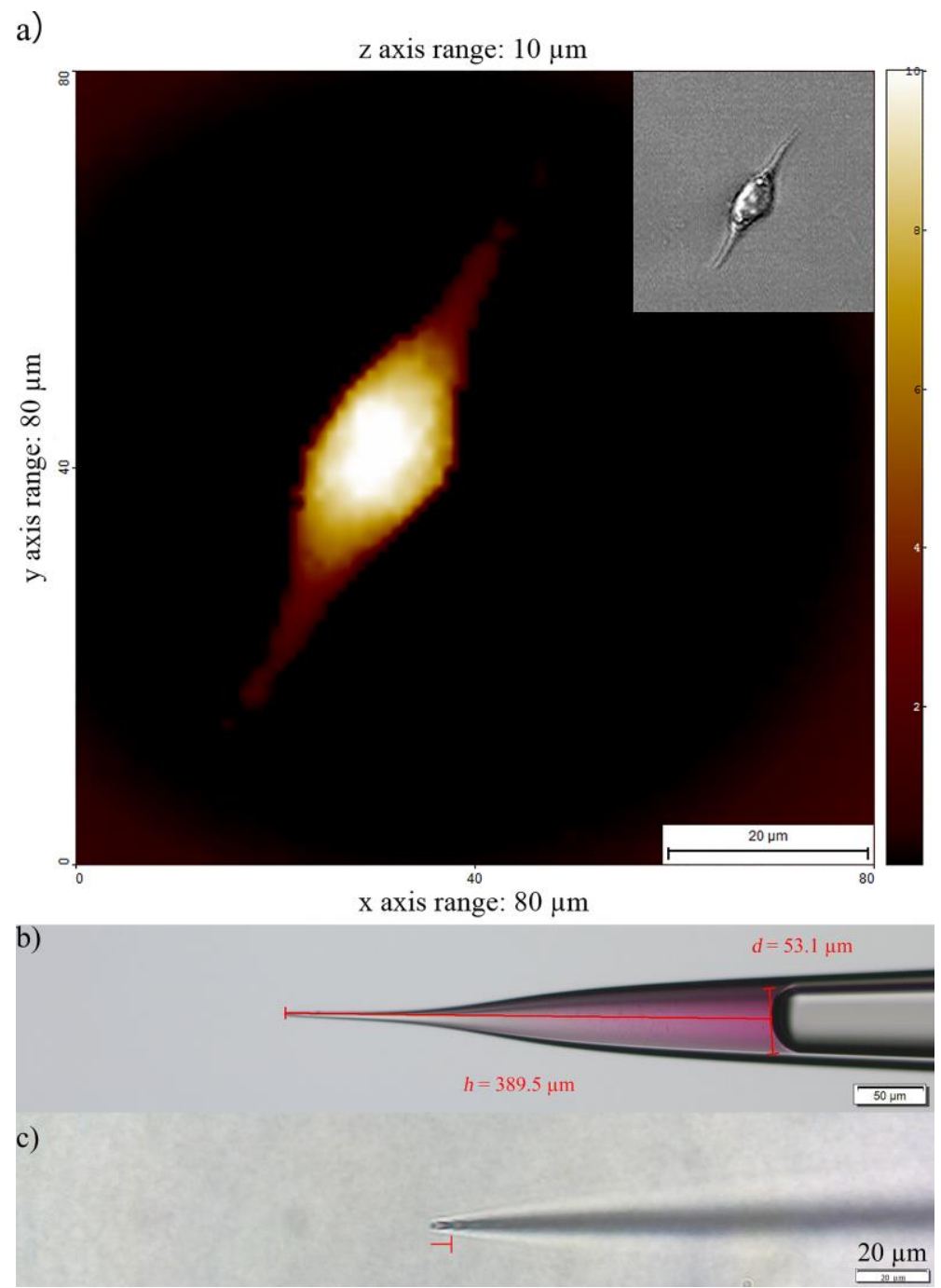

Figure S10. a) Determination of the volume of single PC-12 cells by scanning ion conductance microscopy (Scan area: 80x80 $\mu \mathrm{m}$; Step: $1 \mu \mathrm{m}$ ). The bright-field image of the cell for SICM analysis was inserted in the upper right corner; b) Determination of the volume of sampled content from single Allium cepa cells; c): Determination of the volume of sampled content from single PC-12 cells. 

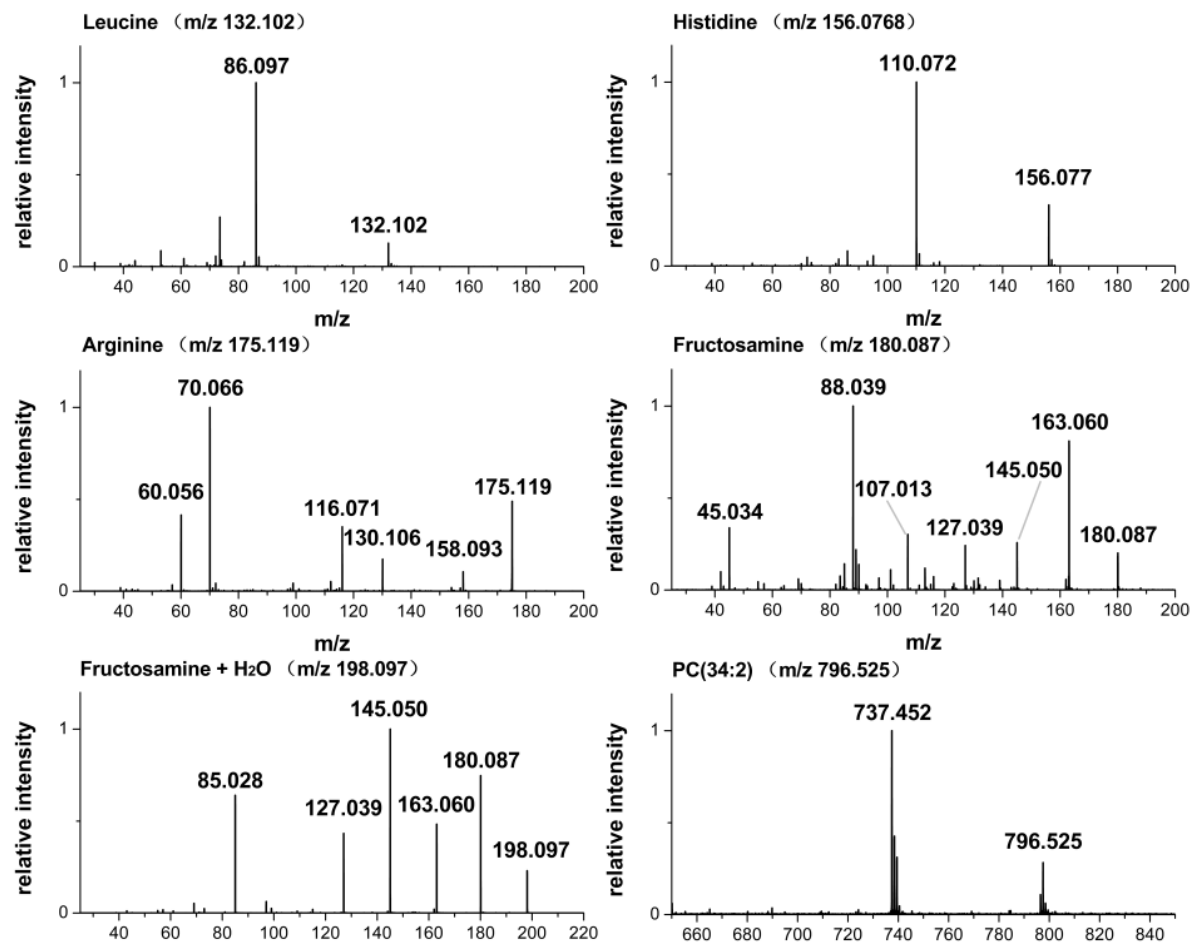
$\mathrm{PC}(34: 2) \quad(\mathrm{m} / \mathrm{z} 796.525)$
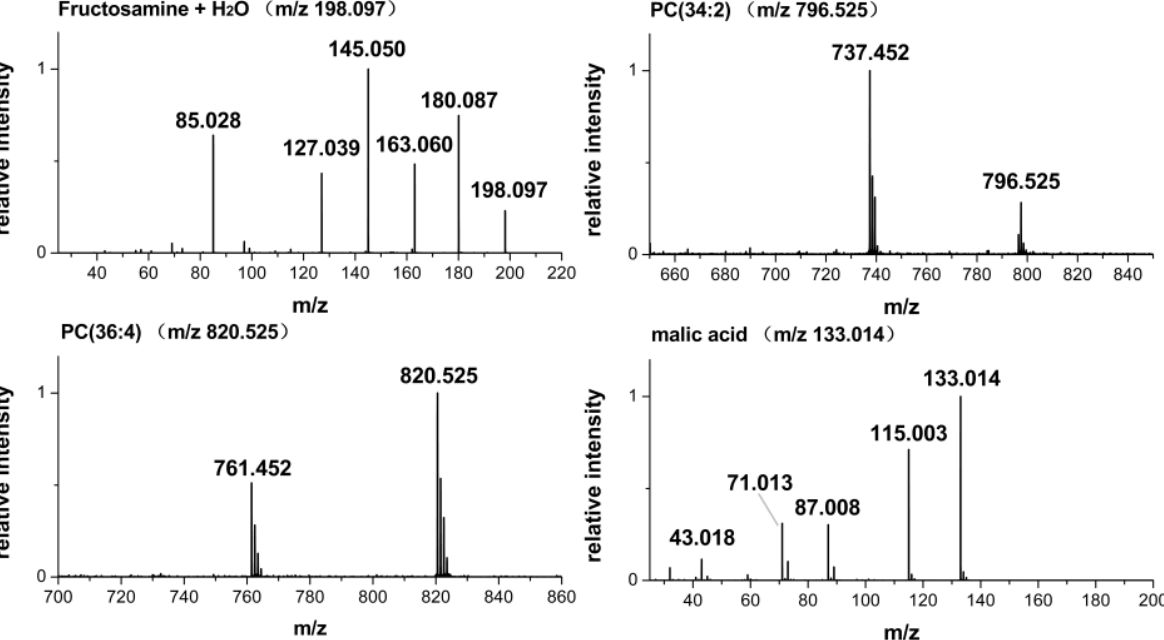

malic acid $(\mathrm{m} / \mathrm{z}$ 133.014)
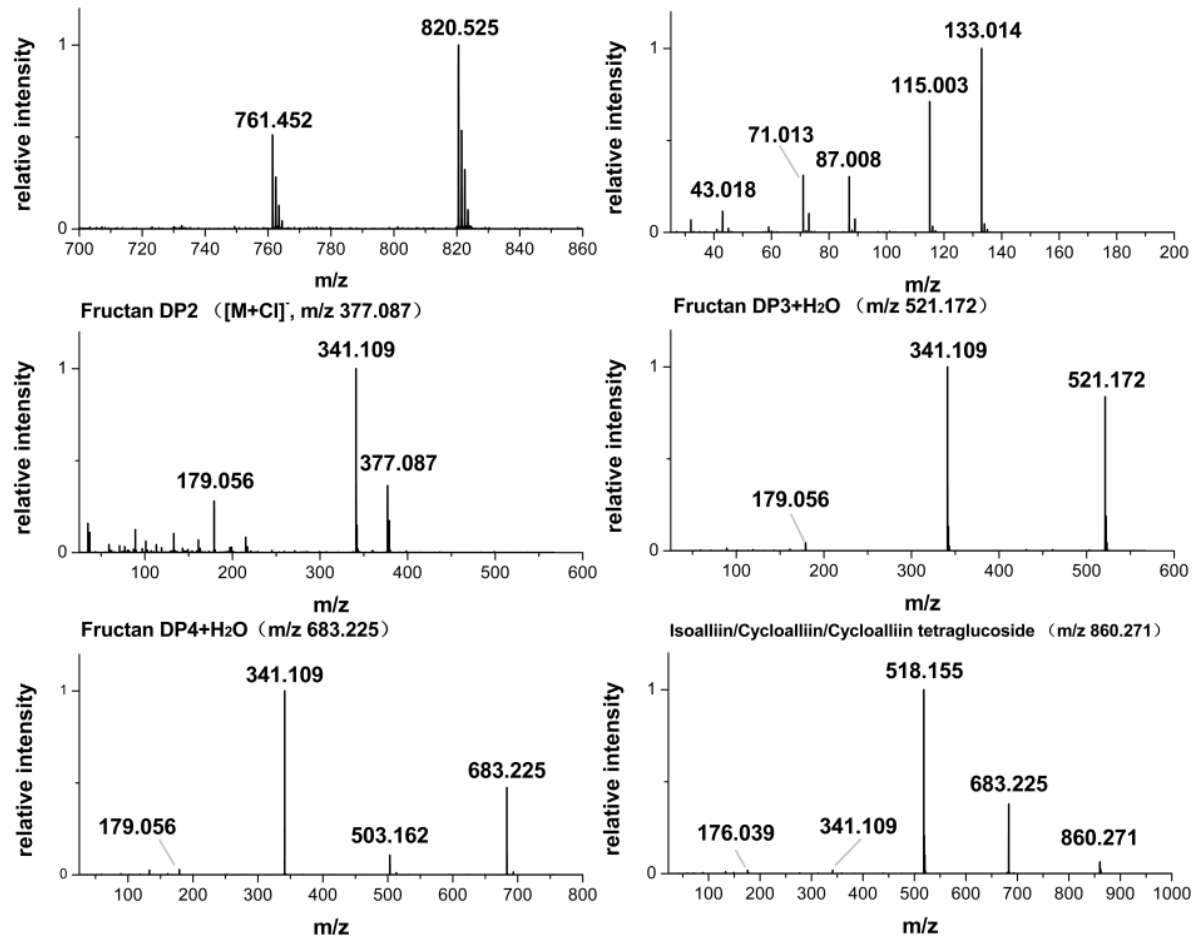

Figure S11. Typical tandem mass spectra obtained from single Allium cepa cell samples. 

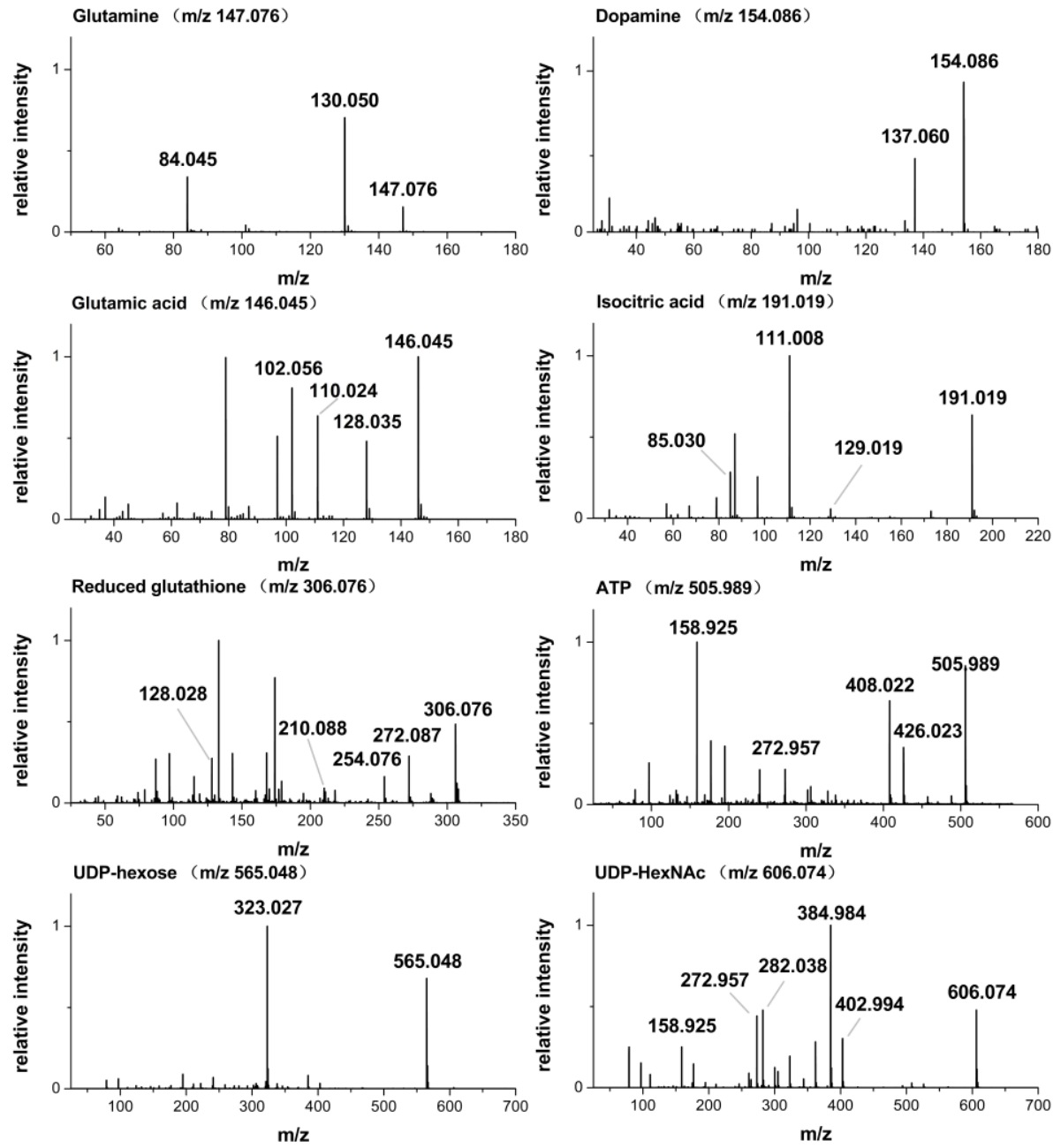

Figure S12. Typical tandem mass spectra obtained from single PC-12 cell samples. 
Table S1. Negative ion assignments from single Allium cepa cell samples based on accurate mass measurements

\begin{tabular}{|c|c|c|c|c|}
\hline $\mathbf{m} / \mathbf{z}$ (measured) & m/z (calculated) & $\begin{array}{c}\Delta(\mathrm{m} / \mathrm{z}) \\
\mathrm{mDa}\end{array}$ & Name & Formula \\
\hline 133.0144 & 133.0142 & 0.2 & Malic acid & {$\left[\mathrm{C}_{4} \mathrm{H}_{6} \mathrm{O}_{5}-\mathrm{H}\right]^{-}$} \\
\hline 145.0621 & 145.0619 & 0.2 & Glutamine & {$\left[\mathrm{C}_{5} \mathrm{H}_{10} \mathrm{~N}_{2} \mathrm{O}_{3}-\mathrm{H}\right]^{-}$} \\
\hline 161.0453 & 161.0455 & -0.2 & Anhydrofructose & {$\left[\mathrm{C}_{6} \mathrm{H}_{10} \mathrm{O}_{5}-\mathrm{H}\right]^{-}$} \\
\hline 175.0250 & 175.0248 & 0.2 & Ascorbic acid & {$\left[\mathrm{C}_{6} \mathrm{H}_{8} \mathrm{O}_{6}-\mathrm{H}\right]^{-}$} \\
\hline 176.0388 & 176.0387 & 0.1 & Isoalliin/cycloalliin/cycloalliin & {$\left[\mathrm{C}_{6} \mathrm{H}_{11} \mathrm{NO}_{3} \mathrm{~S}-\mathrm{H}\right]$} \\
\hline 179.0562 & 179.0561 & 0.1 & Fructose & {$\left[\mathrm{C}_{6} \mathrm{H}_{12} \mathrm{O}_{6}-\mathrm{H}\right]^{-}$} \\
\hline 191.0194 & 191.0197 & 0.3 & Citric acid & {$\left[\mathrm{C}_{6} \mathrm{H}_{8} \mathrm{O}_{7}\right]^{-}$} \\
\hline 215.0323 & 215.0328 & -0.5 & Fructose & {$\left[\mathrm{C}_{6} \mathrm{H}_{12} \mathrm{O}_{6}+\mathrm{Cl}\right]^{-}$} \\
\hline 341.1079 & 341.1089 & -1.0 & Fructan (DP2) & {$\left[\mathrm{C}_{12} \mathrm{H}_{22} \mathrm{O}_{11}-\mathrm{H}\right]^{-}$} \\
\hline 356.1025 & 356.1021 & 0.4 & Isoalliin/Cycloalliin/Cycloalliin glucoside & {$\left[\mathrm{C}_{12} \mathrm{H}_{23} \mathrm{O}_{9} \mathrm{NS}-\mathrm{H}\right]$} \\
\hline 359.1188 & 359.1195 & -0.7 & Fructan $\left(\mathrm{DP} 2+\mathrm{H}_{2} \mathrm{O}\right)$ & {$\left[\mathrm{C}_{12} \mathrm{H}_{24} \mathrm{O}_{12}-\mathrm{H}\right]^{-}$} \\
\hline 377.0845 & 377.0856 & -1.1 & Fructan (DP2) & {$\left[\mathrm{C}_{12} \mathrm{H}_{22} \mathrm{O}_{11}+\mathrm{Cl}\right]$} \\
\hline 395.0953 & 395.0962 & 0.9 & Fructan $\left(\mathrm{DP} 2+\mathrm{H}_{2} \mathrm{O}\right)$ & {$\left[\mathrm{C}_{12} \mathrm{H}_{24} \mathrm{O}_{12}+\mathrm{Cl}\right]^{-}$} \\
\hline 463.0890 & 463.0882 & -0.8 & Quercetin glucoside & {$\left[\mathrm{C}_{21} \mathrm{H}_{20} \mathrm{O}_{12}-\mathrm{H}\right]^{-}$} \\
\hline 477.1033 & 477.1038 & 0.5 & Isorhamnetin glucoside & {$\left[\mathrm{C}_{22} \mathrm{H}_{22} \mathrm{O}_{12}-\mathrm{H}\right]^{-}$} \\
\hline 499.0651 & 499.0649 & -0.2 & Quercetin glucoside & {$\left[\mathrm{C}_{21} \mathrm{H}_{20} \mathrm{O}_{12}+\mathrm{Cl}\right]^{-}$} \\
\hline 503.1609 & 503.1618 & 0.9 & Fructan (DP3) & {$\left[\mathrm{C}_{18} \mathrm{H}_{32} \mathrm{O}_{16}-\mathrm{H}\right]^{-}$} \\
\hline 518.1554 & 518.1549 & -0.5 & Isoalliin/Cycloalliin/Cycloalliin diglucoside & {$\left[\mathrm{C}_{18} \mathrm{H}_{33} \mathrm{O}_{14} \mathrm{NS}-\mathrm{H}\right]$} \\
\hline 521.1719 & 521.1723 & 0.4 & Fructan $\left(\mathrm{DP} 3+\mathrm{H}_{2} \mathrm{O}\right)$ & {$\left[\mathrm{C}_{18} \mathrm{H}_{34} \mathrm{O}_{17}-\mathrm{H}\right]^{-}$} \\
\hline 557.1489 & 557.1490 & 0.1 & Fructan $\left(\mathrm{DP} 3+\mathrm{H}_{2} \mathrm{O}\right)$ & {$\left[\mathrm{C}_{18} \mathrm{H}_{34} \mathrm{O}_{17}+\mathrm{Cl}\right]$} \\
\hline 625.1419 & 625.1410 & -0.9 & Quercetin diglucoside & {$\left[\mathrm{C}_{27} \mathrm{H}_{30} \mathrm{O}_{17}-\mathrm{H}\right]^{-}$} \\
\hline 639.1563 & 639.1567 & 0.4 & Isorhamnetin diglucoside & {$\left[\mathrm{C}_{28} \mathrm{H}_{32} \mathrm{O}_{17}-\mathrm{H}\right]^{-}$} \\
\hline 661.1180 & 661.1177 & -0.3 & Quercetin diglucoside & {$\left[\mathrm{C}_{27} \mathrm{H}_{30} \mathrm{O}_{17}+\mathrm{Cl}\right]$} \\
\hline 665.2140 & 665.2146 & 0.6 & Fructan (DP4) & {$\left[\mathrm{C}_{24} \mathrm{H}_{42} \mathrm{O}_{21}-\mathrm{H}\right]^{-}$} \\
\hline 683.2246 & 683.2251 & 0.5 & Fructan $\left(\mathrm{DP} 4+\mathrm{H}_{2} \mathrm{O}\right)$ & {$\left[\mathrm{C}_{24} \mathrm{H}_{44} \mathrm{O} 22-\mathrm{H}\right]^{-}$} \\
\hline
\end{tabular}




\begin{tabular}{ccccc}
698.2174 & 698.2183 & 0.9 & Isoalliin/Cycloalliin/Cycloalliin triglucoside & {$\left[\mathrm{C}_{24} \mathrm{H}_{45} \mathrm{O}_{20} \mathrm{NS}-\mathrm{H}\right]^{-}$} \\
\hline 827.2670 & 827.2674 & 0.4 & Fructan (DP5) & {$\left[\mathrm{C}_{30} \mathrm{H}_{52} \mathrm{O}_{26}-\mathrm{H}\right]^{-}$} \\
\hline 845.2786 & 845.2780 & -0.6 & Fructan $\left(\mathrm{DP} 5+\mathrm{H}_{2} \mathrm{O}\right)$ & {$\left[\mathrm{C}_{30} \mathrm{H}_{54} \mathrm{O}_{27}-\mathrm{H}\right]^{-}$} \\
\hline 860.2708 & 860.2711 & 0.3 & Isoalliin/Cycloalliin/Cycloalliin & \\
\hline 863.2446 & 863.2441 & -0.5 & tetraglucoside & {$\left[\mathrm{C}_{30} \mathrm{H}_{55} \mathrm{O}_{25} \mathrm{NS}-\mathrm{H}\right]^{-}$} \\
\hline
\end{tabular}


Table S2. Positive ion assignments from single Allium cepa cell samples based on accurate mass measurements

\begin{tabular}{|c|c|c|c|c|}
\hline $\begin{array}{c}\quad \mathbf{m} / \mathbf{z} \\
\text { (measured) }\end{array}$ & $\begin{array}{c}\mathbf{m} / \mathbf{z} \\
\text { (calculated) }\end{array}$ & $\Delta(\mathbf{m} / \mathbf{z}) \mathbf{m D a}$ & Name & Formula \\
\hline 132.1021 & 132.1019 & -0.2 & Leucine & {$\left[\mathrm{C}_{6} \mathrm{H}_{13} \mathrm{NO}_{2}+\mathrm{H}\right]^{+}$} \\
\hline 147.0767 & 147.0764 & -0.3 & Glutamine & {$\left[\mathrm{C}_{5} \mathrm{H}_{10} \mathrm{~N}_{2} \mathrm{O}_{3}+\mathrm{H}\right]^{+}$} \\
\hline 156.0769 & 156.0768 & -0.1 & Histidine & {$\left[\mathrm{C}_{6} \mathrm{H}_{9} \mathrm{~N}_{3} \mathrm{O}_{2}+\mathrm{H}\right]^{+}$} \\
\hline 163.0604 & 163.0601 & -0.3 & Anhydrofructose & {$\left[\mathrm{C}_{6} \mathrm{H}_{10} \mathrm{O}_{5}+\mathrm{H}\right]^{+}$} \\
\hline 170.058 & 170.0578 & -0.2 & Leucine & {$\left[\mathrm{C}_{6} \mathrm{H}_{13} \mathrm{NO}_{2}+\mathrm{K}\right]^{+}$} \\
\hline 178.0534 & 178.0532 & -0.2 & Isoalliin/cycloalliin/cycloalliin & {$\left[\mathrm{C}_{6} \mathrm{H}_{11} \mathrm{NO}_{3} \mathrm{~S}+\mathrm{H}\right]^{+}$} \\
\hline 180.0867 & 180.0866 & -0.1 & Fructosamine & {$\left[\mathrm{C}_{6} \mathrm{H}_{13} \mathrm{NO}_{5}+\mathrm{H}\right]^{+}$} \\
\hline 181.0705 & 181.0707 & 0.2 & Fructose & {$\left[\mathrm{C}_{6} \mathrm{H}_{12} \mathrm{O}_{6}+\mathrm{H}\right]^{+}$} \\
\hline 185.0326 & 185.0323 & -0.3 & Glutamine & {$\left[\mathrm{C}_{5} \mathrm{H}_{10} \mathrm{~N}_{2} \mathrm{O}_{3}+\mathrm{H}\right]^{+}$} \\
\hline 198.0975 & 198.0972 & -0.3 & Fructosamine $+\mathrm{H}_{2} \mathrm{O}$ & {$\left[\mathrm{C}_{6} \mathrm{H}_{15} \mathrm{NO}_{6}+\mathrm{H}\right]^{+}$} \\
\hline 203.0529 & 203.0526 & -0.3 & Fructose & {$\left[\mathrm{C}_{6} \mathrm{H}_{12} \mathrm{O}_{6}+\mathrm{Na}\right]^{+}$} \\
\hline 216.0095 & 216.0091 & -0.4 & Isoalliin/cycloalliin/cycloalliin & {$\left[\mathrm{C}_{6} \mathrm{H}_{11} \mathrm{NO}_{3} \mathrm{~S}+\mathrm{K}\right]^{+}$} \\
\hline 219.0267 & 219.0265 & -0.2 & Fructose & {$\left[\mathrm{C}_{6} \mathrm{H}_{12} \mathrm{O}_{6}+\mathrm{K}\right]^{+}$} \\
\hline 325.1125 & 325.1129 & 0.4 & Fructan(DP2)- $\mathrm{H}_{2} \mathrm{O}$ & {$\left[\mathrm{C}_{12} \mathrm{H}_{20} \mathrm{O}_{10}+\mathrm{H}\right]^{+}$} \\
\hline 343.1231 & 343.1235 & 0.4 & Fructan(DP2) & {$\left[\mathrm{C}_{12} \mathrm{H}_{22} \mathrm{O}_{11}+\mathrm{H}\right]^{+}$} \\
\hline 361.1338 & 361.1341 & 0.3 & Fructan $(\mathrm{DP} 2)+\mathrm{H}_{2} \mathrm{O}$ & {$\left[\mathrm{C}_{12} \mathrm{H}_{24} \mathrm{O}_{12}+\mathrm{H}\right]^{+}$} \\
\hline 365.1045 & 365.1054 & 0.9 & Fructan(DP2) & {$\left[\mathrm{C}_{12} \mathrm{H}_{22} \mathrm{O}_{11}+\mathrm{Na}\right]^{+}$} \\
\hline 381.0802 & 381.0794 & -0.8 & Fructan(DP2) & {$\left[\mathrm{C}_{12} \mathrm{H}_{22} \mathrm{O}_{11}+\mathrm{K}\right]^{+}$} \\
\hline 383.1146 & 383.116 & 1.4 & $\operatorname{Fructan}(\mathrm{DP} 2)+\mathrm{H}_{2} \mathrm{O}$ & {$\left[\mathrm{C}_{12} \mathrm{H}_{24} \mathrm{O}_{12}+\mathrm{Na}\right]^{+}$} \\
\hline 399.0900 & 399.0899 & -0.1 & Fructan $(\mathrm{DP} 2)+\mathrm{H}_{2} \mathrm{O}$ & {$\left[\mathrm{C}_{12} \mathrm{H}_{24} \mathrm{O}_{12}+\mathrm{K}\right]^{+}$} \\
\hline 465.1017 & 465.1028 & 1.1 & Quercetin glucoside & {$\left[\mathrm{C}_{21} \mathrm{H}_{20} \mathrm{O}_{12}+\mathrm{Na}\right]^{+}$} \\
\hline 487.0855 & 487.0847 & -0.8 & Quercetin glucoside & {$\left[\mathrm{C}_{21} \mathrm{H}_{20} \mathrm{O}_{12}+\mathrm{Na}\right]^{+}$} \\
\hline 501.1007 & 501.1003 & -0.4 & Isorhamnetin glucoside & {$\left[\mathrm{C}_{22} \mathrm{H}_{22} \mathrm{O}_{12}+\mathrm{K}\right]^{+}$} \\
\hline 503.0593 & 503.0586 & -0.7 & Quercetin glucoside & {$\left[\mathrm{C}_{21} \mathrm{H}_{20} \mathrm{O}_{12}+\mathrm{K}\right]^{+}$} \\
\hline 517.0739 & 517.0743 & 0.4 & Isorhamnetin glucoside & {$\left[\mathrm{C}_{22} \mathrm{H}_{22} \mathrm{O}_{12}+\mathrm{K}\right]^{+}$} \\
\hline
\end{tabular}




\begin{tabular}{|c|c|c|c|c|}
\hline 527.1563 & 527.1583 & 2 & Fructan(DP3) & {$\left[\mathrm{C}_{18} \mathrm{H}_{32} \mathrm{O}_{16}+\mathrm{Na}\right]^{+}$} \\
\hline 543.1341 & 543.1322 & -1.9 & Fructan(DP3) & {$\left[\mathrm{C}_{18} \mathrm{H}_{32} \mathrm{O}_{16}+\mathrm{K}\right]^{+}$} \\
\hline 545.1682 & 545.1688 & 0.6 & Fructan $(\mathrm{DP} 3)+\mathrm{H}_{2} \mathrm{O}$ & {$\left[\mathrm{C}_{18} \mathrm{H}_{34} \mathrm{O}_{17}+\mathrm{Na}\right]^{+}$} \\
\hline 561.143 & 561.1428 & -0.2 & Fructan(DP3)+ $\mathrm{H}_{2} \mathrm{O}$ & {$\left[\mathrm{C}_{18} \mathrm{H}_{34} \mathrm{O}_{17}+\mathrm{K}\right]^{+}$} \\
\hline 563.179 & 563.1794 & 0.4 & Fructan $(\mathrm{DP} 3)+2 \mathrm{H}_{2} \mathrm{O}$ & {$\left[\mathrm{C}_{18} \mathrm{H}_{36} \mathrm{O}_{18}+\mathrm{Na}\right]^{+}$} \\
\hline 579.1531 & 579.1533 & 0.2 & Fructan $(\mathrm{DP} 3)+2 \mathrm{H}_{2} \mathrm{O}$ & {$\left[\mathrm{C}_{18} \mathrm{H}_{36} \mathrm{O}_{18}+\mathrm{K}\right]^{+}$} \\
\hline 627.1570 & 627.1556 & -1.4 & Quercetin diglucoside & {$\left[\mathrm{C}_{27} \mathrm{H}_{30} \mathrm{O}_{17}+\mathrm{H}\right]^{+}$} \\
\hline 649.1379 & 649.1375 & -0.4 & Quercetin diglucoside & {$\left[\mathrm{C}_{27} \mathrm{H}_{30} \mathrm{O}_{17}+\mathrm{Na}\right]^{+}$} \\
\hline 665.1125 & 665.1115 & -1 & Quercetin diglucoside & {$\left[\mathrm{C}_{27} \mathrm{H}_{30} \mathrm{O}_{17}+\mathrm{K}\right]^{+}$} \\
\hline 705.1870 & 705.1850 & -2 & Fructan(DP4) & {$\left[\mathrm{C}_{24} \mathrm{H}_{42} \mathrm{O}_{21}+\mathrm{K}\right]^{+}$} \\
\hline 723.1966 & 723.1956 & -1 & Fructan(DP4) $+\mathrm{H}_{2} \mathrm{O}$ & {$\left[\mathrm{C}_{24} \mathrm{H}_{44} \mathrm{O}_{22}+\mathrm{K}\right]^{+}$} \\
\hline 741.2070 & 741.2061 & -0.9 & Fructan(DP4) $+2 \mathrm{H}_{2} \mathrm{O}$ & {$\left[\mathrm{C}_{24} \mathrm{H}_{46} \mathrm{O}_{23}+\mathrm{K}\right]^{+}$} \\
\hline 759.2159 & 759.2167 & 0.8 & Fructan(DP4) $+3 \mathrm{H}_{2} \mathrm{O}$ & {$\left[\mathrm{C}_{24} \mathrm{H}_{48} \mathrm{O}_{24}+\mathrm{K}\right]^{+}$} \\
\hline 796.5257 & 796.5253 & -0.4 & $\mathrm{PC}(34: 2)$ & {$\left[\mathrm{C}_{42} \mathrm{H}_{80} \mathrm{NO}_{8} \mathrm{P}+\mathrm{K}\right]^{+}$} \\
\hline 820.5259 & 820.5253 & -0.6 & $\mathrm{PC}(36: 4)$ & {$\left[\mathrm{C}_{44} \mathrm{H}_{80} \mathrm{NO}_{8} \mathrm{P}+\mathrm{K}\right]^{+}$} \\
\hline 831.2217 & 831.2167 & -5 & Fructan(DP5)-2 $\mathrm{H}_{2} \mathrm{O}$ & {$\left[\mathrm{C}_{30} \mathrm{H}_{48} \mathrm{O}_{24}+\mathrm{K}\right]^{+}$} \\
\hline 849.2253 & 849.2273 & 2 & Fructan(DP5)- $\mathrm{H}_{2} \mathrm{O}$ & {$\left[\mathrm{C}_{30} \mathrm{H}_{50} \mathrm{O}_{25}+\mathrm{K}\right]^{+}$} \\
\hline 867.2367 & 867.2378 & 1.1 & Fructan(DP5) & {$\left[\mathrm{C}_{30} \mathrm{H}_{52} \mathrm{O}_{26}+\mathrm{K}\right]^{+}$} \\
\hline 885.25 & 885.2484 & -1.6 & Fructan(DP5) $+\mathrm{H}_{2} \mathrm{O}$ & {$\left[\mathrm{C}_{30} \mathrm{H}_{54} \mathrm{O}_{27}+\mathrm{K}\right]^{+}$} \\
\hline 903.2604 & 903.259 & -1.4 & Fructan(DP5) $+2 \mathrm{H}_{2} \mathrm{O}$ & {$\left[\mathrm{C}_{30} \mathrm{H}_{56} \mathrm{O}_{28}+\mathrm{K}\right]^{+}$} \\
\hline 921.27 & 921.2695 & -0.5 & Fructan(DP5) $+3 \mathrm{H}_{2} \mathrm{O}$ & {$\left[\mathrm{C}_{30} \mathrm{H}_{58} \mathrm{O}_{29}+\mathrm{K}\right]^{+}$} \\
\hline 939.2786 & 939.2801 & 1.5 & Fructan(DP5) $+4 \mathrm{H}_{2} \mathrm{O}$ & {$\left[\mathrm{C}_{30} \mathrm{H}_{60} \mathrm{O}_{30}+\mathrm{K}\right]^{+}$} \\
\hline 975.255 & 975.259 & 4 & Fructan(DP6)-3 $\mathrm{H}_{2} \mathrm{O}$ & {$\left[\mathrm{C}_{36} \mathrm{H}_{56} \mathrm{O}_{28}+\mathrm{K}\right]^{+}$} \\
\hline 993.2675 & 993.2695 & 2 & Fructan(DP6)-2 $\mathrm{H}_{2} \mathrm{O}$ & {$\left[\mathrm{C}_{36} \mathrm{H}_{58} \mathrm{O}_{29}+\mathrm{K}\right]^{+}$} \\
\hline 1011.283 & 1011.2801 & -2.9 & Fructan(DP6) $-\mathrm{H}_{2} \mathrm{O}$ & {$\left[\mathrm{C}_{36} \mathrm{H}_{60} \mathrm{O}_{30}+\mathrm{K}\right]^{+}$} \\
\hline 1029.291 & 1029.2907 & -0.3 & Fructan(DP6) & {$\left[\mathrm{C}_{36} \mathrm{H}_{62} \mathrm{O}_{31}+\mathrm{K}\right]^{+}$} \\
\hline 1047.3051 & 1047.3012 & -3.9 & Fructan(DP6) $+\mathrm{H}_{2} \mathrm{O}$ & {$\left[\mathrm{C}_{36} \mathrm{H}_{64} \mathrm{O}_{32}+\mathrm{K}\right]^{+}$} \\
\hline 1065.3145 & 1065.3118 & -2.7 & Fructan(DP6) $+2 \mathrm{H}_{2} \mathrm{O}$ & {$\left[\mathrm{C}_{36} \mathrm{H}_{66} \mathrm{O}_{33}+\mathrm{K}\right]^{+}$} \\
\hline 1083.3235 & 1083.3224 & -1.1 & Fructan(DP6) $+3 \mathrm{H}_{2} \mathrm{O}$ & {$\left[\mathrm{C}_{36} \mathrm{H}_{68} \mathrm{O}_{34}+\mathrm{K}\right]^{+}$} \\
\hline
\end{tabular}




\begin{tabular}{lllll}
1101.3339 & 1101.3329 & -1 & Fructan(DP6)+4 $\mathrm{H}_{2} \mathrm{O}$ & {$\left[\mathrm{C}_{36} \mathrm{H}_{70} \mathrm{O}_{35}+\mathrm{K}\right]^{+}$} \\
\hline 1119.3425 & 1119.3435 & 1 & Fructan(DP6) $+5 \mathrm{H}_{2} \mathrm{O}$ & {$\left[\mathrm{C}_{36} \mathrm{H}_{72} \mathrm{O}_{36}+\mathrm{K}\right]^{+}$} \\
\hline
\end{tabular}


Table S3. Negative ion assignments from single PC-12 cell samples based on accurate mass measurements

\begin{tabular}{|c|c|c|c|c|}
\hline $\begin{array}{c}\mathbf{m} / \mathbf{z} \\
\text { (measured) }\end{array}$ & $\begin{array}{c}\mathbf{m} / \mathbf{z} \\
\text { (calculated) }\end{array}$ & $\begin{array}{c}\Delta(\mathbf{m} / \mathbf{z}) \\
\mathbf{m D a}\end{array}$ & Name & Formula \\
\hline 89.0241 & 89.0244 & 0.3 & Lactic acid & {$\left[\mathrm{C}_{3} \mathrm{H}_{6} \mathrm{O}_{3}-\mathrm{H}\right]^{-}$} \\
\hline 132.0303 & 132.0302 & -0.1 & Aspartic & {$\left[\mathrm{C}_{4} \mathrm{H}_{7} \mathrm{NO}_{4}-\mathrm{H}\right]^{-}$} \\
\hline 145.0614 & 145.0619 & 0.5 & Glutamine & {$\left[\mathrm{C}_{5} \mathrm{H}_{10} \mathrm{~N}_{2} \mathrm{O}_{3}-\mathrm{H}\right]^{-}$} \\
\hline 146.0463 & 146.0459 & -0.4 & Glutamic acid & {$\left[\mathrm{C}_{5} \mathrm{H}_{9} \mathrm{NO}_{4}-\mathrm{H}\right]^{-}$} \\
\hline 191.0189 & 191.0197 & 0.8 & Isocitric acid & {$\left[\mathrm{C}_{6} \mathrm{H}_{8} \mathrm{O}_{7}-\mathrm{H}\right]^{-}$} \\
\hline 259.0216 & 259.0224 & 0.8 & glucose/fructose phosphate & {$\left[\mathrm{C}_{6} \mathrm{H}_{13} \mathrm{O}_{9} \mathrm{P}-\mathrm{H}\right]^{-}$} \\
\hline 306.0775 & 306.0765 & -1.0 & Reduced glutathione & {$\left[\mathrm{C}_{10} \mathrm{H}_{17} \mathrm{~N}_{3} \mathrm{O}_{6} \mathrm{~S}-\mathrm{H}\right]^{-}$} \\
\hline 323.0276 & 323.0286 & 1.0 & UMP & 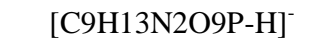 \\
\hline 328.0591 & 328.0585 & -0.6 & Reduced glutathione & {$\left[\mathrm{C}_{10} \mathrm{H}_{17} \mathrm{~N}_{3} \mathrm{O}_{6} \mathrm{~S}+\mathrm{Na}-2 \mathrm{H}\right]^{-}$} \\
\hline 346.0563 & 346.0558 & -0.5 & AMP & {$\left[\mathrm{C}_{10} \mathrm{H}_{14} \mathrm{~N}_{5} \mathrm{O}_{7} \mathrm{P}-\mathrm{H}\right]^{-}$} \\
\hline 402.9966 & 402.9949 & -1.7 & UDP & {$\left[\mathrm{C}_{9} \mathrm{H}_{14} \mathrm{~N}_{2} \mathrm{O}_{12} \mathrm{P}_{2}-\mathrm{H}\right]^{-}$} \\
\hline 426.0220 & 426.0221 & 0.1 & $\mathrm{ADP}$ & {$\left[\mathrm{C}_{10} \mathrm{H}_{15} \mathrm{~N}_{5} \mathrm{O}_{10} \mathrm{P}_{2}-\mathrm{H}\right]^{-}$} \\
\hline 448.0050 & 448.0041 & -0.9 & $\mathrm{ADP}$ & {$\left[\mathrm{C}_{10} \mathrm{H}_{15} \mathrm{~N}_{5} \mathrm{O}_{10} \mathrm{P}_{2}+\mathrm{Na}-2 \mathrm{H}\right]^{-}$} \\
\hline 505.9886 & 505.9885 & -0.1 & ATP & {$\left[\mathrm{C}_{10} \mathrm{H}_{16} \mathrm{~N}_{5} \mathrm{O}_{13} \mathrm{P}_{3}-\mathrm{H}\right]^{-}$} \\
\hline 565.0482 & 565.0477 & -0.5 & UDP-hexose & {$\left[\mathrm{C}_{15} \mathrm{H}_{24} \mathrm{~N}_{2} \mathrm{O}_{17} \mathrm{P}_{2}-\mathrm{H}\right]^{-}$} \\
\hline 606.0747 & 606.0743 & -0.4 & UDP-HexNAc & {$\left[\mathrm{C}_{17} \mathrm{H}_{27} \mathrm{~N}_{3} \mathrm{O}_{17} \mathrm{P}_{2}-\mathrm{H}\right]^{-}$} \\
\hline 662.1012 & 662.1018 & 0.6 & NAD & {$\left[\mathrm{C}_{21} \mathrm{H}_{27} \mathrm{~N}_{7} \mathrm{O}_{14} \mathrm{P}_{2}-\mathrm{H}\right]^{-}$} \\
\hline 682.5913 & 682.5910 & -0.3 & Cer(d18:1/24:1(15Z)) & {$\left[\mathrm{C}_{42} \mathrm{H}_{81} \mathrm{NO}_{3}+\mathrm{Cl}\right]^{-}$} \\
\hline 684.6052 & 684.6067 & 1.5 & $\begin{array}{l}\text { Ceramide (d18:1/24:0)/ } \\
\text { Cer(d18:0/24:1(15Z)) }\end{array}$ & {$\left[\mathrm{C}_{42} \mathrm{H}_{83} \mathrm{NO}_{3}-\mathrm{H}\right]^{-}$} \\
\hline 716.5235 & 716.5236 & 0.1 & $\mathrm{PE}(32: 2)$ & {$\left[\mathrm{C}_{39} \mathrm{H}_{76} \mathrm{NO}_{8} \mathrm{P}-\mathrm{H}\right]^{-}$} \\
\hline 737.5384 & 737.5370 & -1.4 & $\mathrm{SM}(\mathrm{d} 18: 0 / 16: 1(9 \mathrm{Z}))$ & {$\left[\mathrm{C}_{39} \mathrm{H}_{79} \mathrm{~N}_{2} \mathrm{O}_{6} \mathrm{P}+\mathrm{Cl}\right]^{-}$} \\
\hline 742.5305 & 742.5392 & 8.7 & $\operatorname{PE}(36: 2)$ & {$\left[\mathrm{C}_{41} \mathrm{H}_{78} \mathrm{NO}_{8} \mathrm{P}-\mathrm{H}\right]^{-}$} \\
\hline 744.5532 & 744.5549 & 1.7 & $\mathrm{PE}(36: 1) / \mathrm{PC}(33: 1)$ & {$\left[\mathrm{C}_{41} \mathrm{H}_{80} \mathrm{NO}_{8} \mathrm{P}-\mathrm{H}\right]^{-}$} \\
\hline 746.5126 & 746.5130 & 0.4 & $\operatorname{PE}(38: 6)$ & {$\left[\mathrm{C}_{43} \mathrm{H}_{74} \mathrm{NO}_{7} \mathrm{P}-\mathrm{H}\right]^{-}$} \\
\hline
\end{tabular}




\begin{tabular}{|c|c|c|c|c|}
\hline 747.5193 & 747.5182 & -1.1 & $\operatorname{PG}(34: 1)$ & {$\left[\mathrm{C}_{40} \mathrm{H}_{77} \mathrm{O}_{10} \mathrm{P}-\mathrm{H}\right]^{-}$} \\
\hline 748.5249 & 748.5287 & 3.8 & $\operatorname{PE}(38: 5)$ & {$\left[\mathrm{C}_{43} \mathrm{H}_{76} \mathrm{NO}_{7} \mathrm{P}-\mathrm{H}\right]^{-}$} \\
\hline 752.5399 & 752.5366 & -3.3 & $\mathrm{PC}(32: 0)$ & {$\left[\mathrm{C}_{40} \mathrm{H}_{80} \mathrm{NO}_{7} \mathrm{P}+\mathrm{Cl}\right]^{-}$} \\
\hline 764.5167 & 764.5236 & 6.9 & $\operatorname{PE}(38: 5)$ & {$\left[\mathrm{C}_{43} \mathrm{H}_{76} \mathrm{NO}_{8} \mathrm{P}-\mathrm{H}\right]^{-}$} \\
\hline 766.5212 & 766.5159 & -5.3 & $\mathrm{PC}(32: 1) / \mathrm{PE}(35: 1)$ & {$\left[\mathrm{C}_{40} \mathrm{H}_{78} \mathrm{NO}_{8} \mathrm{P}+\mathrm{Cl}\right]^{-}$} \\
\hline 768.5306 & 768.5316 & 1.0 & $\mathrm{PC}(32: 0) / \mathrm{PE}(35: 0)$ & {$\left[\mathrm{C}_{40} \mathrm{H}_{80} \mathrm{NO}_{8} \mathrm{P}+\mathrm{Cl}\right]^{-}$} \\
\hline 771.5223 & 771.5182 & -4.1 & $\operatorname{PG}(36: 3)$ & {$\left[\mathrm{C}_{42} \mathrm{H}_{77} \mathrm{O}_{10} \mathrm{P}-\mathrm{H}\right]^{-}$} \\
\hline 773.5352 & 773.5338 & -1.4 & $\operatorname{PG}(36: 2)$ & {$\left[\mathrm{C}_{42} \mathrm{H}_{79} \mathrm{O}_{10} \mathrm{P}-\mathrm{H}\right]^{-}$} \\
\hline 775.5474 & 775.5495 & 2.1 & $\operatorname{PG}(36: 1)$ & {$\left[\mathrm{C}_{42} \mathrm{H}_{81} \mathrm{O}_{10} \mathrm{P}-\mathrm{H}\right]^{-}$} \\
\hline 780.5593 & 780.5549 & -4.4 & $\mathrm{PC}(36: 4)$ & {$\left[\mathrm{C}_{44} \mathrm{H}_{80} \mathrm{NO}_{8} \mathrm{P}-\mathrm{H}\right]^{-}$} \\
\hline 782.5601 & 782.5705 & 10.4 & $\mathrm{PC}(36: 3)$ & {$\left[\mathrm{C}_{44} \mathrm{H}_{82} \mathrm{NO}_{8} \mathrm{P}-\mathrm{H}\right]^{-}$} \\
\hline 788.5455 & 788.5447 & -0.8 & $\operatorname{PS}(36: 1)$ & {$\left[\mathrm{C}_{42} \mathrm{H}_{80} \mathrm{NO}_{10} \mathrm{P}-\mathrm{H}\right]^{-}$} \\
\hline 792.5333 & 792.5316 & -1.7 & $\mathrm{PC}(34: 2) / \mathrm{PE}(37: 2)$ & {$\left[\mathrm{C}_{42} \mathrm{H}_{80} \mathrm{NO}_{8} \mathrm{P}+\mathrm{Cl}\right]^{-}$} \\
\hline 794.5478 & 794.5472 & -0.6 & $\mathrm{PC}(34: 1) / \mathrm{PE}(37: 1)$ & {$\left[\mathrm{C}_{42} \mathrm{H}_{82} \mathrm{NO}_{8} \mathrm{P}+\mathrm{Cl}\right]^{-}$} \\
\hline 806.5702 & 806.5705 & 0.3 & $\mathrm{PC}(38: 5)$ & {$\left[\mathrm{C}_{46} \mathrm{H}_{82} \mathrm{NO}_{8} \mathrm{P}-\mathrm{H}\right]^{-}$} \\
\hline 808.5119 & 808.5134 & 1.5 & $\operatorname{PS}(38: 5)$ & {$\left[\mathrm{C}_{44} \mathrm{H}_{76} \mathrm{NO}_{10} \mathrm{P}-\mathrm{H}\right]^{-}$} \\
\hline 818.5400 & 818.5472 & 7.2 & $\operatorname{PS}(36: 3)$ & {$\left[\mathrm{C}_{44} \mathrm{H}_{82} \mathrm{NO}_{8} \mathrm{P}+\mathrm{Cl}\right]^{+}$} \\
\hline 820.5625 & 820.5629 & 0.4 & $\mathrm{PC}(36: 2)$ & {$\left[\mathrm{C}_{44} \mathrm{H}_{84} \mathrm{NO}_{8} \mathrm{P}+\mathrm{Cl}\right]^{+}$} \\
\hline 822.5719 & 822.5785 & 6.6 & $\mathrm{PC}(36: 1)$ & {$\left[\mathrm{C}_{44} \mathrm{H}_{86} \mathrm{NO}_{8} \mathrm{P}+\mathrm{Cl}\right]^{+}$} \\
\hline 834.5333 & 834.5291 & -4.2 & $\operatorname{PS}(40: 6)$ & {$\left[\mathrm{C}_{46} \mathrm{H}_{78} \mathrm{NO}_{10} \mathrm{P}-\mathrm{H}\right]^{+}$} \\
\hline 836.5493 & 836.5447 & -4.6 & $\operatorname{PS}(40: 5)$ & {$\left[\mathrm{C}_{46} \mathrm{H}_{80} \mathrm{NO}_{10} \mathrm{P}-\mathrm{H}\right]^{+}$} \\
\hline 842.5414 & 842.5472 & 5.8 & $\mathrm{PC}(38: 5)$ & {$\left[\mathrm{C}_{46} \mathrm{H}_{82} \mathrm{NO}_{8} \mathrm{P}+\mathrm{Cl}\right]^{+}$} \\
\hline 844.5633 & 844.5629 & -0.4 & $\mathrm{PC}(38: 4)$ & {$\left[\mathrm{C}_{46} \mathrm{H}_{84} \mathrm{NO}_{8} \mathrm{P}+\mathrm{Cl}\right]^{+}$} \\
\hline 846.5579 & 846.5785 & 20.6 & $\mathrm{PC}(38: 3)$ & {$\left[\mathrm{C}_{46} \mathrm{H}_{86} \mathrm{NO}_{8} \mathrm{P}+\mathrm{C}\right]^{+}$} \\
\hline 847.6410 & 847.6465 & 5.5 & $\operatorname{SM}(d 18: 1 / 24: 1(15 Z))$ & {$\left[\mathrm{C}_{47} \mathrm{H}_{93} \mathrm{~N}_{2} \mathrm{O}_{6} \mathrm{P}-\mathrm{H}\right]^{+}$} \\
\hline 861.5550 & 861.5499 & -5.1 & $\mathrm{PI}(36: 2)$ & {$\left[\mathrm{C}_{45} \mathrm{H}_{83} \mathrm{O}_{13} \mathrm{P}-\mathrm{H}\right]^{+}$} \\
\hline 885.5514 & 885.5499 & -1.5 & $\mathrm{PI}(38: 4)$ & {$\left[\mathrm{C}_{47} \mathrm{H}_{83} \mathrm{O}_{13} \mathrm{P}-\mathrm{H}\right]^{+}$} \\
\hline 887.5658 & 887.5655 & -0.3 & $\mathrm{PI}(38: 3)$ & {$\left[\mathrm{C}_{47} \mathrm{H}_{85} \mathrm{O}_{13} \mathrm{P}-\mathrm{H}\right]$} \\
\hline
\end{tabular}


Table S4. Positive ion assignments from single PC-12 cell samples based on accurate mass measurements

\begin{tabular}{|c|c|c|c|c|}
\hline $\begin{array}{c}\mathrm{m} / \mathbf{z} \\
\text { (measured) }\end{array}$ & $\begin{array}{c}\mathbf{m} / \mathbf{z} \\
\text { (calculated) }\end{array}$ & $\begin{array}{c}\Delta(\mathrm{m} / \mathrm{z}) \\
\mathbf{m D a}\end{array}$ & Name & Formula \\
\hline 116.0707 & 116.0706 & -0.1 & Proline & {$\left[\mathrm{C}_{5} \mathrm{H}_{9} \mathrm{NO}_{2}+\mathrm{H}\right]^{+}$} \\
\hline 118.0862 & 118.0863 & 0.1 & Valine & {$\left[\mathrm{C}_{5} \mathrm{H}_{11} \mathrm{NO}_{2}+\mathrm{H}\right]^{+}$} \\
\hline 120.0657 & 120.0655 & -0.2 & Threonine & {$\left[\mathrm{C}_{4} \mathrm{H}_{9} \mathrm{NO}_{3}+\mathrm{H}\right]^{+}$} \\
\hline 122.0273 & 122.0270 & -0.3 & Cysteine & {$\left[\mathrm{C}_{3} \mathrm{H}_{7} \mathrm{NO}_{2} \mathrm{~S}+\mathrm{H}\right]^{+}$} \\
\hline 132.0771 & 132.0768 & -0.3 & Creatine & {$\left[\mathrm{C}_{4} \mathrm{H}_{9} \mathrm{~N}_{3} \mathrm{O}_{2}+\mathrm{H}\right]^{+}$} \\
\hline 134.0449 & 134.0448 & -0.1 & Aspartic & {$\left[\mathrm{C}_{4} \mathrm{H}_{7} \mathrm{NO}_{4}+\mathrm{H}\right]^{+}$} \\
\hline 147.0769 & 147.0764 & -0.5 & Glutamine & {$\left[\mathrm{C}_{5} \mathrm{H}_{10} \mathrm{~N}_{2} \mathrm{O}_{3}+\mathrm{H}\right]^{+}$} \\
\hline 148.0601 & 148.0604 & 0.3 & Glutamic acid & {$\left[\mathrm{C}_{5} \mathrm{H}_{9} \mathrm{NO}_{4}+\mathrm{H}\right]^{+}$} \\
\hline 154.0869 & 154.0863 & -0.6 & Dopamine & {$\left[\mathrm{C}_{8} \mathrm{H}_{11} \mathrm{O}_{2} \mathrm{~N}+\mathrm{H}\right]^{+}$} \\
\hline 156.0763 & 156.0768 & 0.5 & Histidine & {$\left[\mathrm{C}_{6} \mathrm{H}_{9} \mathrm{~N}_{3} \mathrm{O}_{2}+\mathrm{H}\right]^{+}$} \\
\hline 176.0556 & 176.0553 & -0.3 & N-Acetyl-L-aspartic acid & {$\left[\mathrm{C}_{6} \mathrm{H}_{9} \mathrm{NO}_{5}+\mathrm{H}\right]^{+}$} \\
\hline 182.0815 & 182.0812 & -0.3 & Tyrosine & {$\left[\mathrm{C}_{9} \mathrm{H}_{11} \mathrm{NO}_{3}+\mathrm{H}\right]^{+}$} \\
\hline 198.0374 & 198.0373 & -0.1 & N-Acetyl-L-aspartic acid & {$\left[\mathrm{C}_{6} \mathrm{H}_{9} \mathrm{NO}_{5}+\mathrm{H}\right]^{+}$} \\
\hline 204.1235 & 204.1230 & -0.5 & L-Acetylcarnitine & {$\left[\mathrm{C}_{9} \mathrm{H}_{17} \mathrm{NO}_{4}+\mathrm{H}\right]^{+}$} \\
\hline 205.0975 & 205.0972 & -0.3 & Tryptophan & {$\left[\mathrm{C}_{11} \mathrm{H}_{12} \mathrm{~N}_{2} \mathrm{O}_{2}+\mathrm{H}\right]^{+}$} \\
\hline 220.1183 & 220.1179 & -0.4 & Pantothenic acid & {$[\mathrm{C} 9 \mathrm{H} 17 \mathrm{NO} 5+\mathrm{H}]^{+}$} \\
\hline 269.0890 & 269.0880 & -1.0 & Inosine & {$\left[\mathrm{C}_{10} \mathrm{H}_{12} \mathrm{~N}_{4} \mathrm{O}_{5}+\mathrm{H}\right]^{+}$} \\
\hline 308.0917 & 308.0911 & -0.6 & Glutathione & {$\left[\mathrm{C}_{10} \mathrm{H}_{17} \mathrm{~N}_{3} \mathrm{O}_{6} \mathrm{~S}+\mathrm{H}\right]^{+}$} \\
\hline 322.0773 & 322.0769 & -0.4 & Beta-Citryl-L-glutamic acid & {$\left[\mathrm{C}_{11} \mathrm{H}_{15} \mathrm{NO}_{10}+\mathrm{H}\right]^{+}$} \\
\hline 330.0737 & 330.0730 & -0.7 & Glutathione & {$\left[\mathrm{C}_{10} \mathrm{H}_{17} \mathrm{~N}_{3} \mathrm{O}_{6} \mathrm{~S}+\mathrm{Na}\right]^{+}$} \\
\hline 346.0481 & 346.0470 & -1.1 & Glutathione & {$\left[\mathrm{C}_{10} \mathrm{H}_{17} \mathrm{~N}_{3} \mathrm{O}_{6} \mathrm{~S}+\mathrm{K}\right]^{+}$} \\
\hline 725.5564 & 725.5568 & 0.4 & $\operatorname{SM}(\mathrm{d} 18: 0 / 16: 1(9 \mathrm{Z}))$ & {$\left[\mathrm{C}_{39} \mathrm{H}_{79} \mathrm{~N}_{2} \mathrm{O}_{6} \mathrm{P}+\mathrm{Na}\right]^{+}$} \\
\hline 741.5340 & 741.5307 & -3.3 & $\operatorname{SM}(\mathrm{d} 18: 0 / 16: 1(9 Z))$ & {$\left[\mathrm{C}_{39} \mathrm{H}_{79} \mathrm{~N}_{2} \mathrm{O}_{6} \mathrm{P}+\mathrm{K}\right]^{+}$} \\
\hline 754.5360 & 754.5357 & -0.3 & $\mathrm{PC}(32: 1)$ & {$\left[\mathrm{C}_{40} \mathrm{H}_{78} \mathrm{NO}_{8} \mathrm{P}+\mathrm{Na}\right]^{+}$} \\
\hline 756.5471 & 756.5514 & 4.3 & $\mathrm{PC}(32: 0)$ & {$\left[\mathrm{C}_{40} \mathrm{H}_{80} \mathrm{NO}_{8} \mathrm{P}+\mathrm{Na}\right]^{+}$} \\
\hline
\end{tabular}




\begin{tabular}{|c|c|c|c|c|}
\hline 772.5237 & 772.5252 & 1.5 & $\operatorname{PE}(38: 5)$ & {$\left[\mathrm{C}_{43} \mathrm{H}_{76} \mathrm{NO}_{7} \mathrm{P}+\mathrm{Na}\right]^{+}$} \\
\hline 778.5391 & 778.5357 & -3.4 & $\mathrm{PC}(34: 3)$ & {$\left[\mathrm{C}_{42} \mathrm{H}_{78} \mathrm{NO}_{8} \mathrm{P}+\mathrm{Na}\right]^{+}$} \\
\hline 780.5513 & 780.5514 & 0.1 & $\mathrm{PC}(34: 2)$ & {$\left[\mathrm{C}_{42} \mathrm{H}_{80} \mathrm{NO}_{8} \mathrm{P}+\mathrm{Na}\right]^{+}$} \\
\hline 782.5664 & 782.5670 & 0.6 & $\mathrm{PC}(34: 1)$ & {$\left[\mathrm{C}_{42} \mathrm{H}_{82} \mathrm{NO}_{8} \mathrm{P}+\mathrm{Na}\right]^{+}$} \\
\hline 790.5538 & 790.5593 & 5.5 & $\operatorname{PS}(36: 1)$ & {$\left[\mathrm{C}_{42} \mathrm{H}_{80} \mathrm{NO}_{10} \mathrm{P}+\mathrm{H}\right]^{+}$} \\
\hline 792.5759 & 792.5749 & -1.0 & $\operatorname{PS}(36: 0)$ & {$\left[\mathrm{C}_{42} \mathrm{H}_{82} \mathrm{NO}_{10} \mathrm{P}+\mathrm{H}\right]^{+}$} \\
\hline 794.5876 & 794.5907 & 3.1 & $\begin{array}{l}\text { Glucosylceramide } \\
\text { (d18:1/20:0) }\end{array}$ & {$\left[\mathrm{C}_{44} \mathrm{H}_{85} \mathrm{NO}_{8}+\mathrm{K}\right]^{+}$} \\
\hline 796.5615 & 796.5617 & 0.2 & $\operatorname{PE}(38: 1)$ & {$\left[\mathrm{C}_{43} \mathrm{H}_{84} \mathrm{NO}_{7} \mathrm{P}+\mathrm{K}\right]^{+}$} \\
\hline 798.5412 & 798.5410 & -0.2 & $\mathrm{PC}(34: 1)$ & {$\left[\mathrm{C}_{42} \mathrm{H}_{82} \mathrm{NO}_{8} \mathrm{P}+\mathrm{K}\right]^{+}$} \\
\hline 804.5528 & 804.5514 & -1.4 & $\mathrm{PC}(36: 4)$ & {$\left[\mathrm{C}_{44} \mathrm{H}_{80} \mathrm{NO}_{8} \mathrm{P}+\mathrm{Na}\right]^{+}$} \\
\hline 806.5654 & 806.5670 & 1.6 & $\mathrm{PC}(36: 3)$ & {$\left[\mathrm{C}_{44} \mathrm{H}_{82} \mathrm{NO}_{8} \mathrm{P}+\mathrm{Na}\right]^{+}$} \\
\hline 808.5823 & 808.5827 & 0.4 & $\mathrm{PC}(36: 2)$ & {$\left[\mathrm{C}_{44} \mathrm{H}_{84} \mathrm{NO}_{8} \mathrm{P}+\mathrm{Na}\right]^{+}$} \\
\hline 810.5974 & 810.5983 & 0.9 & $\mathrm{PC}(36: 1)$ & {$\left[\mathrm{C}_{44} \mathrm{H}_{86} \mathrm{NO}_{8} \mathrm{P}+\mathrm{Na}\right]^{+}$} \\
\hline 824.5562 & 824.5566 & 0.4 & $\mathrm{PC}(36: 2)$ & {$\left[\mathrm{C}_{44} \mathrm{H}_{84} \mathrm{NO}_{8} \mathrm{P}+\mathrm{K}\right]^{+}$} \\
\hline 826.5699 & 826.5723 & 2.4 & $\mathrm{PC}(36: 1)$ & {$\left[\mathrm{C}_{44} \mathrm{H}_{86} \mathrm{NO}_{8} \mathrm{P}+\mathrm{K}\right]^{+}$} \\
\hline 835.6601 & 835.6663 & 6.2 & $\mathrm{SM}(\mathrm{d} 18: 1 / 24: 1(15 \mathrm{Z}))$ & {$\left[\mathrm{C}_{47} \mathrm{H}_{93} \mathrm{~N}_{2} \mathrm{O}_{6} \mathrm{P}+\mathrm{Na}\right]^{+}$} \\
\hline
\end{tabular}

